Supporting Information

\title{
A Preinstalled Protic Cation as a Switch for Superprotonic Conduction in a Metal-Organic Framework
}

Kazuya Otsubo, ${ }^{*}{ }^{\dagger}$ Shuya Nagayama, ${ }^{\dagger}$ Shogo Kawaguchi, ${ }^{\ddagger}$ Kunihisa Sugimoto, and Hiroshi Kitagawa*,†

'Division of Chemistry, Graduate School of Science, Kyoto University, Kitashirakawa-Oiwakecho, Sakyo-ku, Kyoto 606-8502, Japan

†apan Synchrotron Radiation Research Institute (JASRI), SPring-8, 1-1-1 Kouto, Sayo-cho, Sayo-gun, Hyogo 679-5198, Japan

*e-mail: kazuya@kuchem.kyoto-u.ac.jp; kitagawa@kuchem.kyoto-u.ac.jp.

Table of Contents

1. Materials and Methods pp.S2-S5

2. Supplementary Discussion pp.S6-S7

3. Figures S1-S23 and Tables S1-S4 pp.S8-S26

4. References pp.S27-S28 


\section{Materials and Methods}

General. All reagents were purchased from FUJIFILM Wako Pure Chemical Co. Japan, TCI Japan, and Sigma-Aldrich Japan, and were used without further purification. Raman spectrum was recorded with a Jasco NRS-5100 spectrometer at room temperature (RT). A Nd:YAG Laser provided the exciting line $\left(E_{\mathrm{i}}=532 \mathrm{~nm}\right)$. The electronic absorption spectrum was collected with a Thermo Nicolet NEXUS 670 FT-IR and a Jasco V-570 spectrometers at RT. X-ray photoelectron spectroscopy (XPS) measurements were performed using an ESCA-3400 spectrometer (Shimadzu Corp.) equipped with $\mathrm{Mg} \mathrm{K \alpha}$ radiation as the exciting source (1253.6 $\mathrm{eV})$. The binding energies were calibrated with the $\mathrm{C} 1 s$ signal. Thermogravimetric analysis (TGA) was performed with a TG-DTA 2000SA (NETZSCH Japan) at a heating rate of 5 $\mathrm{K} / \mathrm{min}$ in a constant flow of $\mathrm{N}_{2}$ gas. Water vapor adsorption/desorption isotherms were measured using a BELSORP-max apparatus (MicrotracBEL Corp.). The polycrystalline powder $(\sim 100 \mathrm{mg})$ was dried under high vacuum $\left(<10^{-1} \mathrm{~Pa}\right)$ at RT for 3 days prior to measurement. Elemental analyses were performed using MT-5 and MT-6 CHN recorders (Yanaco) and XS-2100H (Mitsubishi Chemical Analytech.) at the Organic Microanalysis Laboratory, Kyoto University.

\section{Synthesis.}

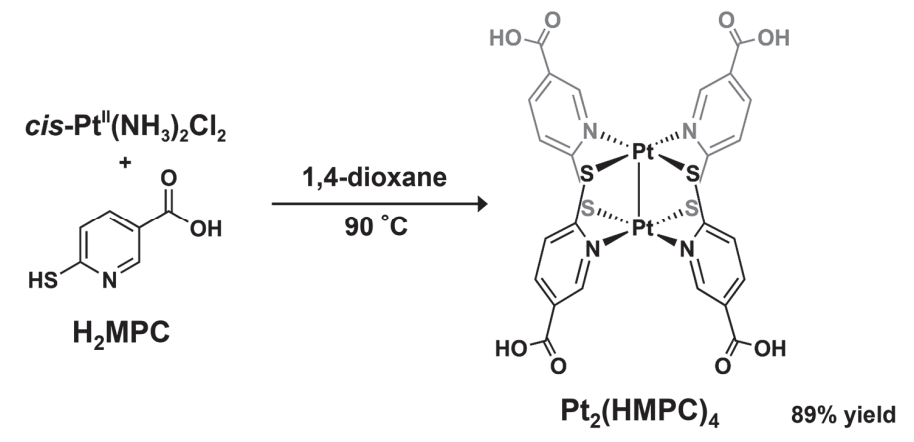

Scheme S1. Synthetic scheme for the Pt dimer complex, $\mathrm{Pt}_{2}(\mathrm{HMPC})_{4}$.

The synthetic procedure for the divalent $\mathrm{Pt}$ dimer complex, $\mathrm{Pt}_{2}(\mathrm{HMPC}) 4$, is shown in Scheme $\mathrm{S} 1$. Cisplatin (cis- $\mathrm{Pt}\left(\mathrm{NH}_{3}\right)_{2} \mathrm{Cl}_{2}, 200 \mathrm{mg}, 0.67 \mathrm{mmol}$ ) and 6-mercaptopyridine-3-carboxylic acid ( $\left.\mathrm{H}_{2} \mathrm{MPC}, 223 \mathrm{mg}, 1.34 \mathrm{mmol}\right)$ were added to 1,4-dioxane $(30 \mathrm{ml})$. This solution was stirred at $90{ }^{\circ} \mathrm{C}$ for $12 \mathrm{~h}$. After cooling, yellow precipitates of $\mathrm{Pt}_{2}(\mathrm{HMPC}) 4$ were collected by filtration (Yield: $375 \mathrm{mg}, 89 \%$ ). Needle-shaped single crystals suitable for X-ray 
crystallography were obtained by slow cooling of a hot $\left(70-95{ }^{\circ} \mathrm{C}\right)$ dimethylformamide (DMF) solution. Elemental analysis (\% calcd, \% found for $\left.\mathrm{C}_{24} \mathrm{H}_{16} \mathrm{~N}_{4} \mathrm{O}_{8} \mathrm{Pt}_{2} \mathrm{~S}_{4} \cdot 5.5 \mathrm{DMF} \cdot \mathrm{H}_{2} \mathrm{O}\right)$ : C (34.09, 33.79), H (3.99, 3.97), N (9.33, 9.61).

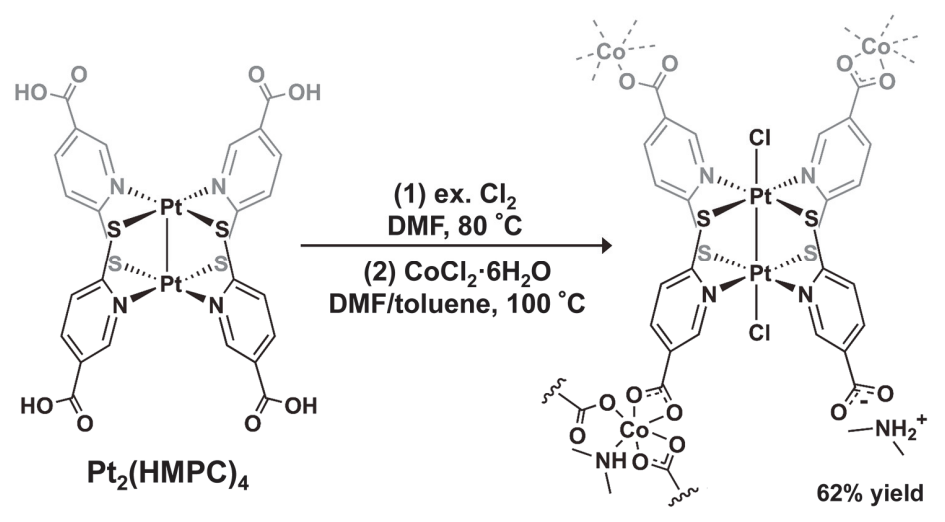

Scheme S2. Synthetic scheme for the novel MOF, $\left[\mathrm{Pt}_{2}(\mathrm{MPC})_{4} \mathrm{Cl}_{2} \mathrm{Co}(\mathrm{DMA})(\mathrm{HDMA}) \cdot \text { guest }\right]_{\mathrm{n}}$ (1, DMA: dimethylamine).

The synthetic procedure for the MOF, 1 is shown in Scheme S2. A DMF solution of $\mathrm{Pt}_{2}(\mathrm{HMPC})_{4}(20 \mathrm{mmol} / \mathrm{L}, 10 \mathrm{ml})$ was treated with $\mathrm{Cl}_{2}$ and stirred at $80{ }^{\circ} \mathrm{C}$ for $12 \mathrm{~h}$. To $3.5 \mathrm{ml}$ of this solution, a DMF solution of $\mathrm{CoCl}_{2} \cdot 6 \mathrm{H}_{2} \mathrm{O}(40 \mathrm{mmol} / \mathrm{L}, 0.5 \mathrm{ml})$ and toluene $(0.5 \mathrm{ml})$ were added and sealed in a screw-capped glass vial $(15 \mathrm{ml})$. After heating at $100{ }^{\circ} \mathrm{C}$ for $72 \mathrm{~h}$, single crystals were obtained by slow cooling (Yield: $55.6 \mathrm{mg}, 62 \%$ based on a Pt dimer complex). Elemental analysis (\% calcd, \% found for $\left.\mathrm{C}_{28} \mathrm{H}_{27} \mathrm{Cl}_{2} \mathrm{CoN}_{6} \mathrm{O}_{8} \mathrm{Pt}_{2} \mathrm{~S}_{4} \cdot \mathrm{DMA} \cdot 0.5 \mathrm{H}_{2} \mathrm{O}\right)$ : $\mathrm{C}(28.20,28.33), \mathrm{H}(2.76,2.87), \mathrm{N}(7.67,7.44), \mathrm{Cl}(5.55,5.65), \mathrm{S}(10.04,10.05)$.

Single-crystal X-ray diffraction (XRD). Single-crystal XRD measurements were carried out using a Bruker SMART APEX II CCD detector with graphite-monochromated Mo Ka radiation $(\lambda=0.71073 \AA)$ at $100 \mathrm{~K}$. The single crystal was mounted on MicroMesh (MiTeGen) with Paraton-N oil (Hampton Research) to avoid the loss of guest molecules. The structures were solved by direct methods $(\operatorname{SIR} 2004)^{1}$ and refined by full-matrix least-squares refinement on $F^{2}$ (SHELXL version 2018/3) ${ }^{2}$ using the CrystalStructure 4.3.2. software. $^{3}$

Data for $\mathrm{Pt}_{2}(\mathrm{HMPC})_{4} \cdot 7 \mathrm{DMF}\left(\mathrm{C}_{45} \mathrm{H}_{65} \mathrm{~N}_{11} \mathrm{O}_{15} \mathrm{Pt}_{2} \mathrm{~S}_{4}\right)$ at $100 \mathrm{~K}: \mathrm{Mr}=1511.44$, crystal dimensions $0.29 \times 0.05 \times 0.03 \mathrm{~mm}^{3}$, monoclinic, space group $C 2 / m$ (no. 12), $a=21.525(3) \AA, b=$ 20.024(3) $\AA, c=6.567(1) \AA, \beta=93.166(2)^{\circ}, V=2826.2(7) \AA^{3}, \mathrm{Z}=2, d_{\text {calc }}=1.776 \mathrm{~g} / \mathrm{cm}^{3}$, $\mathrm{F}(000)=1490.00, \mu=5.145 \mathrm{~mm}^{-1}$, A total of 15076 reflections were collected, of which 3170 
reflections were unique $\left(R_{\text {int }}=0.0215\right)$. Refinement of 224 parameters led to the final $R_{1}=$ $0.0168(I>2 \sigma(I)), \mathrm{w} R_{2}=0.0443$ (all data), goodness of fit $(\mathrm{GOF})=1.099$, and residual electron density $\mathrm{max} / \mathrm{min}=1.27 /-0.55 \mathrm{e}^{-3}$. CCDC reference number 2075516.

Data for $\mathrm{Pt}_{2}(\mathrm{MPC})_{4} \mathrm{Cl}_{2} \mathrm{Co}(\mathrm{DMA})(\mathrm{HDMA}) \cdot 1.5 \mathrm{DMA} \cdot 0.5 \mathrm{H}_{2} \mathrm{O}(\mathbf{1})\left(\mathrm{C}_{31} \mathrm{H}_{38.5} \mathrm{Cl}_{2} \mathrm{CoN}_{7.5} \mathrm{O}_{8.5} \mathrm{Pt}_{2} \mathrm{~S}_{4}\right)$ at $100 \mathrm{~K}: \mathrm{Mr}=1304.487$, crystal dimensions $0.08 \times 0.08 \times 0.07 \mathrm{~mm}^{3}$, monoclinic, space group $P 21 / n$ (no. 14), $a=17.822(2) \AA, b=9.0411(8) \AA, c=30.291(3) \AA, \beta=106.966(1)^{\circ}, V$ $=4668.4(8) \AA^{3}, \mathrm{Z}=4, d_{\text {calc }}=1.847 \mathrm{~g} / \mathrm{cm}^{3}, \mathrm{~F}(000)=2494.00, \mu=6.650 \mathrm{~mm}^{-1}$, A total of 74250 reflections were collected, of which 10162 reflections were unique $\left(R_{\text {int }}=0.0235\right)$. Refinement of 520 parameters led to the final $R_{1}=0.0401(I>2 \sigma(I)), \mathrm{w} R_{2}=0.1167$ (all data), $\mathrm{GOF}=1.092$, and residual electron density $\max / \mathrm{min}=2.65 /-2.15 \mathrm{e}^{-3}$. CCDC reference number 2075517.

Rietveld refinement. Synchrotron powder X-ray diffraction (PXRD) data were measured in the range of $2 \theta=1.5-50^{\circ}$ with a step of $0.01^{\circ}$ at $298 \mathrm{~K}$, using a large Debye-Scherrer camera with imaging plate detector installed on the BL02B2 beamline at SPring-8, Japan. The incident X-rays were monochromated to $21.3 \mathrm{keV}(\lambda=0.58016 \AA$ ) with a Si (111) double-crystal monochromator. Polycrystalline powder samples in different states were sealed in a glass capillary (WJM-Glas Müller GmbH., Borosilicate, $0.3 \mathrm{~mm}$ diameter, $\phi$ ). Original crystal structure of as-synthesized 1 without guest DMA and $\mathrm{H}_{2} \mathrm{O}$ molecules obtained from single-crystal XRD was adopted as an initial framework model for $\mathbf{1 A}$ and $\mathbf{1 H}$. For $\mathbf{1 H}$, the initial structure for Rietveld refinement including adsorbed $\mathrm{H}_{2} \mathrm{O}$ molecules was solved by the simulated annealing method installed on the EXPO2014 program. ${ }^{4}$ After several trials of simulated annealing calculation by varying the number of $\mathrm{H}_{2} \mathrm{O}$ molecules (12-18 molecules/formula), the initial structural model for Rietveld refinement was obtained. The Rietveld refinement was performed using the program RIETAN-FP. ${ }^{5}$ For structure refinement, soft restraints were applied to all bond lengths, bond angles, and dihedral angles to retain molecular geometry. The number of $\mathrm{H}_{2} \mathrm{O}$ molecules from Rietveld refinement was calculated to be 14.5 molecules/formula, which is in good agreement with the result of the $\mathrm{H}_{2} \mathrm{O}$ sorption isotherm ( 16 molecules/formula at 97\% RH). The maximum entropy method (MEM) analysis was performed using structure factors obtained from Rietveld refinements with 
Dysnomia $^{6}$ and VESTA. ${ }^{7}$ In the MEM analysis, the total numbers of electrons were set to expected values from the empirical formula based on the result of the $\mathrm{H}_{2} \mathrm{O}$ sorption isotherm.

The final Rietveld refinement result of $\mathbf{1 A}\left(\mathrm{C}_{28} \mathrm{H}_{27} \mathrm{Cl}_{2} \mathrm{CoN}_{6} \mathrm{O}_{8} \mathrm{Pt}_{2} \mathrm{~S}_{4}\right)$ at $298 \mathrm{~K}$ : Monoclinic, Space Group $P 21 / n$ (no. 14), $a=17.728(2) \AA, b=9.0528(7) \AA, c=30.253(4) \AA, \beta=$ $106.52(1)^{\circ}, V=4654.9(9) \AA^{3}, Z=4, R_{\mathrm{wp}}=5.80 \%, R_{\mathrm{e}}=5.32 \%, R_{\mathrm{B}}=4.71 \%, R_{F}=1.70 \%, S=$ 1.09, CCDC reference number 2075518.

The final Rietveld refinement result of $\mathbf{1 H}\left(\mathrm{C}_{28} \mathrm{H}_{56} \mathrm{Cl}_{2} \mathrm{CoN}_{6} \mathrm{O}_{22.5} \mathrm{Pt}_{2} \mathrm{~S}_{4}\right)$ at $298 \mathrm{~K}$ : Monoclinic, Space Group $P 2{ }_{1} / n$ (no. 14), $a=17.769(1) \AA, b=9.0766(5) \AA, c=30.374(2) \AA, \beta=$ 106.747(6) $)^{\circ}, V=4691.0(6) \AA^{3}, Z=4, R_{\mathrm{wp}}=4.64 \%, R_{\mathrm{e}}=5.10 \%, R_{\mathrm{B}}=2.42 \%, R_{F}=0.83 \%, S=$ 0.91, CCDC reference number 2075519.

Proton conductivity. Alternate current (AC) impedance measurements on pelletized samples $(\sim 10 \mathrm{mg}, \sim 0.9 \mathrm{~mm}$ thickness $\times 2.5 \mathrm{~mm} \phi)$ and single crystals (see Figure S15) were carried out using a Solartron 1260 impedance/gain-phase analyzer and 1296 dielectric interface (frequency range: $10 \mathrm{MHz}-1 \mathrm{~Hz}$ ). Before measurements, the sample was evacuated at RT to remove non-coordinated guests. Relative humidity $(\mathrm{RH})$ and temperature were controlled using an Espec Corp. SH-221. Electrical contacts were made of gold paint and wires (15-25 $\mu \mathrm{m} \phi$ ). The fitting analysis was performed basically using the following equivalent circuit, where $\mathrm{R}$ is a resistor and $\mathrm{CPE}$ is a constant phase element (imperfect capacitor).

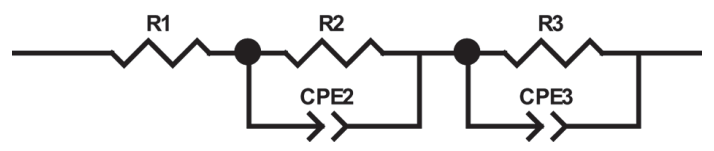

Computational study. Density functional theory (DFT) calculations on structural optimization and vibrational frequency, and time-dependent DFT (TDDFT) calculations on electronic transition were performed using the Gaussian09W package, ${ }^{8}$ and the PBE1PBE functional. The SDD basis set and the effective core potential were used for Pt and Co. 6-31 $\mathrm{g}(\mathrm{d}, \mathrm{p})$ basis set was used for other atoms. For these calculations, a simplified structural model obtained in a single-crystal structure of $\mathbf{1}$ containing one Pt dimer unit linked to one Co unit and one $\mathrm{HDMA}^{+}$unit was used (Figure S7 and Table S2). For the Co site, one DMA and two acetic acids coordinate with Co ion as capping ligands. 


\section{Supplementary Discussion}

Raman and electronic absorption spectra. To investigate the electronic states, Raman and electronic absorption spectra were collected on $\mathbf{1}$. Two vibration modes were clearly observed at 199 and $289 \mathrm{~cm}^{-1}$ in the Raman spectrum (Figure S7a). Based on the DFT calculation using this simple model structure of 1 (Figure S7b), these vibration modes were successfully assigned to $v(\mathrm{Pt}-\mathrm{Pt})$ and $v(\mathrm{Pt}-\mathrm{Cl})$ stretching modes, which strongly reflect the dimer structure. In the electronic absorption spectrum (Figure S8), two absorption bands were observed. From the result of TDDFT calculations, the band at $2.44 \mathrm{eV}$ was assigned to the electronic transition from the highest occupied molecular orbital (HOMO)-1 to the lowest unoccupied molecular orbital (LUMO) (Figure S9 and Table S1). This transition corresponds to the $\mathrm{p} \sigma \rightarrow \mathrm{d} \sigma^{*}$ transition characteristic of the dimer structure as observed in a similar dimer system reported previously. ${ }^{9,10}$ The absorption band at around $4.16 \mathrm{eV}$ can be assigned to the heavily overlapping metal-to-ligand charge-transfer (MLCT) and $n \pi^{*}$ intraligand electronic transitions, as shown in Table S1.

Thermogravimetry. The TGA curve is shown in Figure S12. Gradual and nearly two-step weight losses (denoted as steps 1 and 2) were observed up to $200{ }^{\circ} \mathrm{C}$. The first step can be assigned to the losses of non-coordinated DMA and water in the pore (see Figure S3), whereas the second step is the losses of coordinated DMA and trapped HDMA ${ }^{+}$. The result is in good agreement with the elemental analysis data.

Estimation of the hydrogen-bonding energies in $1 \mathrm{~A}$ and $1 \mathrm{H}$. To obtain further insight into the difference in the experimental activation energy $\left(E_{\mathrm{a}}\right)$ of proton conductivity between anhydrous $(0 \% \mathrm{RH})$ and hydrated $(95 \% \mathrm{RH})$ conditions, we examined hydrogen-bonding energy between MPC and $\mathrm{HDMA}^{+}$in $\mathbf{1 A}$ and $\mathbf{1 H}$. It is generally difficult to estimate the precise energy difference in MOF materials with infinite networked structures. Therefore, we performed a DFT calculation focusing on the intermolecular interaction between one HMPC$\mathrm{HDMA}^{+}$pair using the Gaussian09W package. ${ }^{8}$ The PBE1PBE functional and $6-311++\mathrm{g}(2 \mathrm{~d}$, p) basis set were used. The intermolecular hydrogen-bonding energy was estimated as follows: First, one HMPC- $\mathrm{HDMA}^{+}$pairs were adopted from the crystal structure of $\mathbf{1 A}$ and 1H based on the Rietveld refinement, where hydrogen atoms were placed on the calculated positions. Since one $\mathrm{HDMA}^{+}$cation is shared by two MPC ligand in $\mathbf{1 H}$, two kinds of 
HMPC- $-\mathrm{HDMA}^{+}$pair, type A and type B shown in Figure S23 were considered. Next, intermolecular complexation energy $\left(\Delta E_{\mathrm{cp}}\right)$ was calculated using the counterpoise method. In this method, $\Delta E_{\mathrm{cp}}$ is expressed as $\Delta E_{\mathrm{cp}}=E_{\mathrm{pair}}-E_{\text {monomers }}+\Delta E_{\mathrm{BSSE}}$, where $E_{\mathrm{pair}}, E_{\text {monomers, }}$ and $\triangle E_{\mathrm{BSSE}}$ are total energy of HMPC-HDMA ${ }^{+}$pair, the sum of the total energies of HMPC and $\mathrm{HDMA}^{+}$, and the energy correction of basis set superposition error (BSSE). In these calculations, the atomic positions were fixed to keep the original relative positions as in the X-ray crystal structures. Then, the hydrogen-bonding energy $\left(\Delta E_{\mathrm{H}}\right)$ was estimated from the difference in $\Delta E_{\mathrm{cp}}$ between HMPC-HDMA ${ }^{+}$pair with hydrogen bond $\left(\Delta E_{\mathrm{cp} 1}\right)$ and the same pair without hydrogen bond $\left(\Delta E_{\mathrm{cp} 2}\right)$, which is obtained from simple rotation of $\mathrm{HDMA}^{+}$unit in $\mathrm{HMPC}_{-} \mathrm{HDMA}^{+}$pair, $\Delta E_{\mathrm{H}}=\Delta E_{\mathrm{cp} 2}-\Delta E_{\mathrm{cp} 1}$. For $\mathbf{1 H}$, considering the two types of $\mathrm{HMPC}_{-} \mathrm{HDMA}^{+}$pair (type $\mathrm{A}$ and type $\mathrm{B}$ ), $\Delta E_{\mathrm{H}}$ was estimated from $\Delta E_{\mathrm{H}}=\Delta E_{\mathrm{HA}}+\Delta E_{\mathrm{HB}}$. The calculation results are summarized in Tables S3 and S4. Clear differences in $\Delta E_{\mathrm{cp}}$ were observed between HMPC-HDMA ${ }^{+}$pairs with/without hydrogen bonding (Table S3). The $\Delta E_{\mathrm{H}}$ on $\mathbf{1 A}$ and $\mathbf{1 H}$ were estimated to be 63.2 and $31.7(\mathrm{~kJ} / \mathrm{mol})$, respectively, indicating the strong hydrogen bonding between HMPC and $\mathrm{HDMA}^{+}$in $\mathbf{1 A}$, which provides strongly trapped $\mathrm{HDMA}^{+}$by one MPC unit (Table S4). The difference in $\Delta E_{\mathrm{H}}$ between $\mathbf{1 A}$ and $\mathbf{1 H}$ is calculated as $0.33 \mathrm{eV}$, which is tentatively in good agreement with the difference in $E_{\mathrm{a}}(\sim 0.4 \mathrm{eV})$ obtained from proton conductivity measurements. 


\section{Figures S1-S23 and Tables S1-S4}

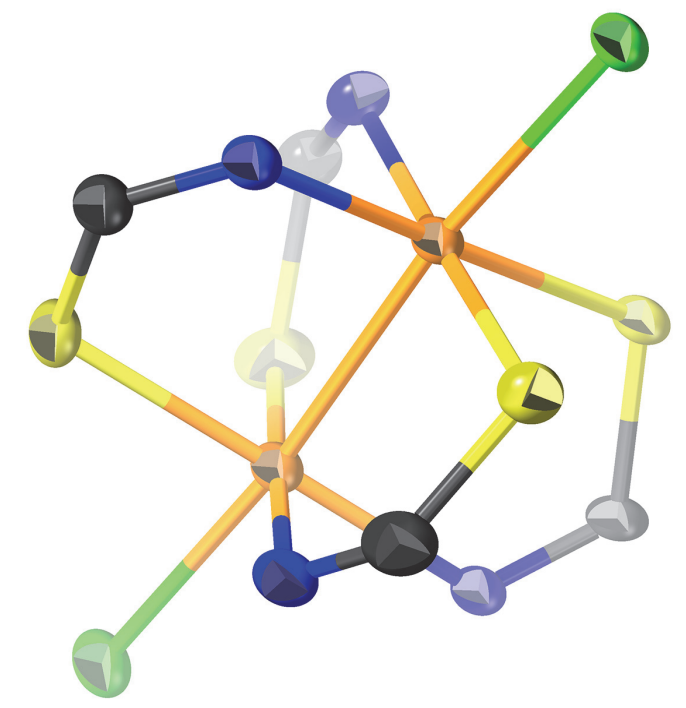

Figure S1. The Pt dimer unit of 1 at $100 \mathrm{~K}$. Color code as in Figure 2. The Pt-Pt, Pt-Cl, Pt-S, and $\mathrm{Pt}-\mathrm{N}$ distances are $2.53,2.54,2.28-2.30$, and $2.11 \AA$, respectively.

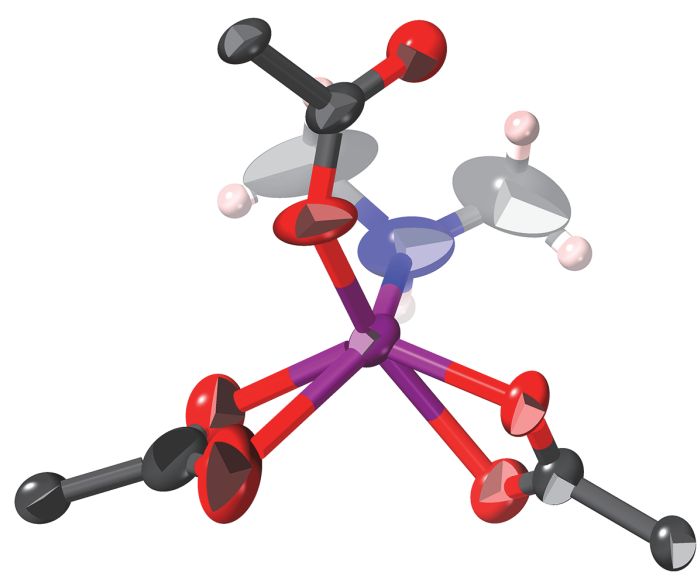

Figure S2. Six-coordinated Co ion in $\mathbf{1}$ at $100 \mathrm{~K}$. Color code as in Figure 2. Co-O and Co-N distances are 1.97-2.47, and $2.00 \AA$, respectively. 


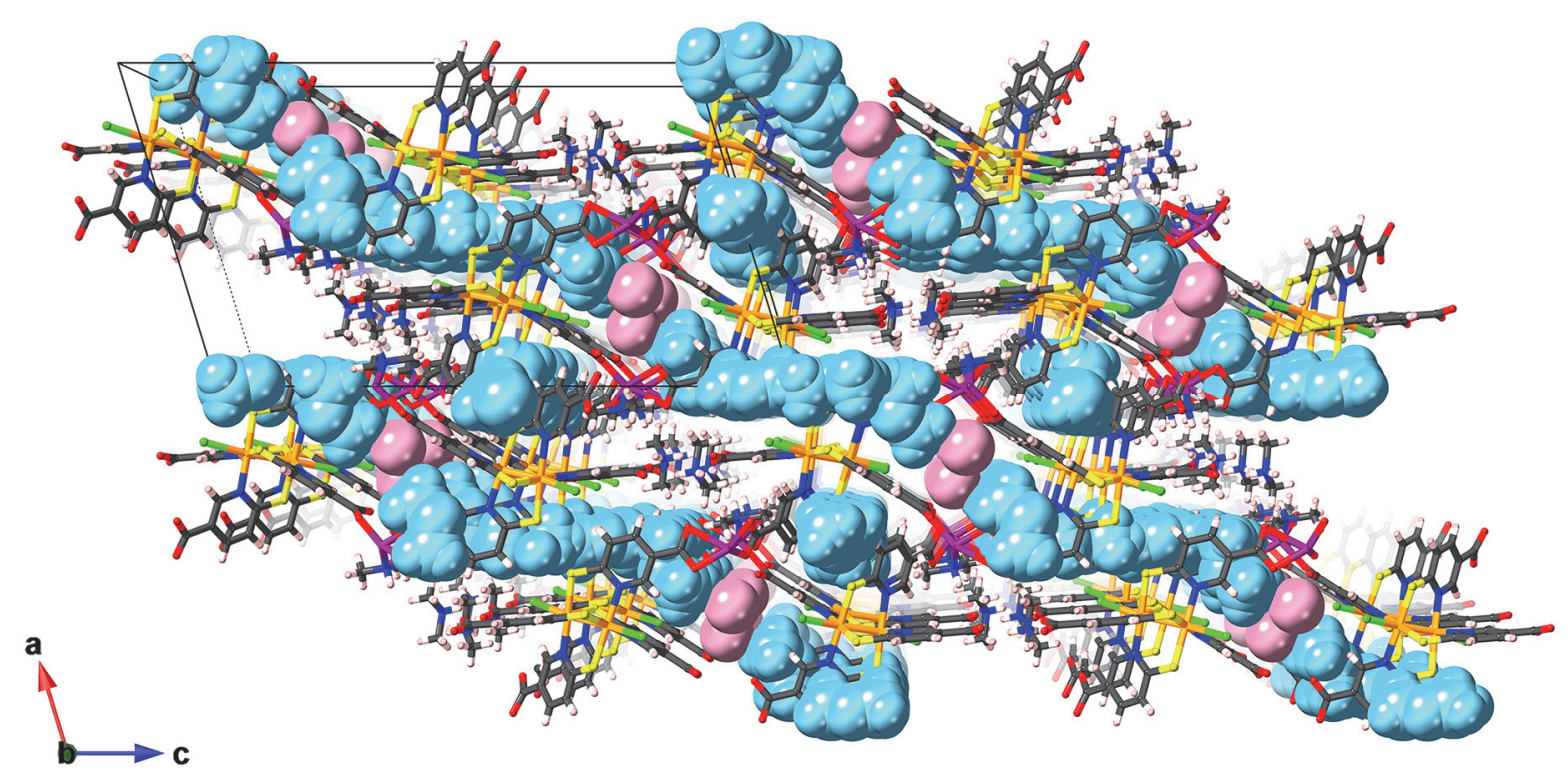

Figure S3. 3D packing structure of 1 including non-coordinated guests (see also Figure 2b). DMA (light blue) and $\mathrm{H}_{2} \mathrm{O}$ (light pink) molecules are drawn in the space-filling model.

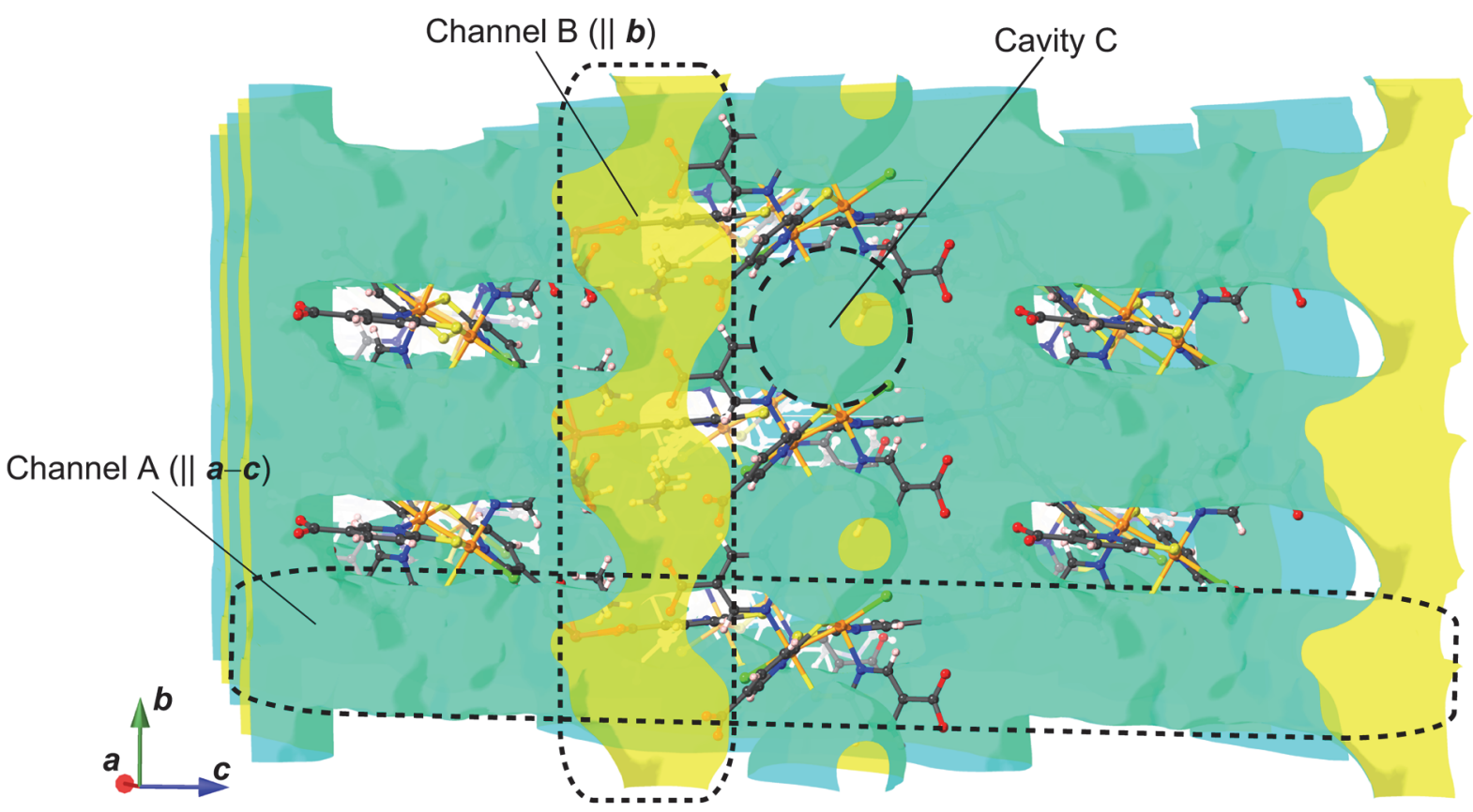

Figure S4. Another view of the void structure of 1 (same as Figure 2c). The 1D channel A is formed along the $\boldsymbol{a}-\boldsymbol{c}$ direction. The $1 \mathrm{D}$ channel $\mathrm{B}$ and isolated cavity $\mathrm{C}$ are also formed along the $\boldsymbol{b}$ direction. Channels A and B are linked (areas surrounded by black dotted line). 
(a)

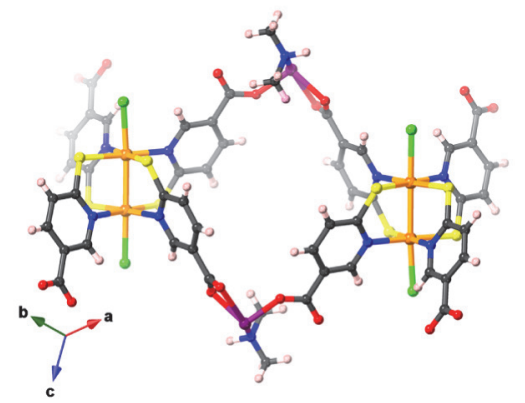

(b)
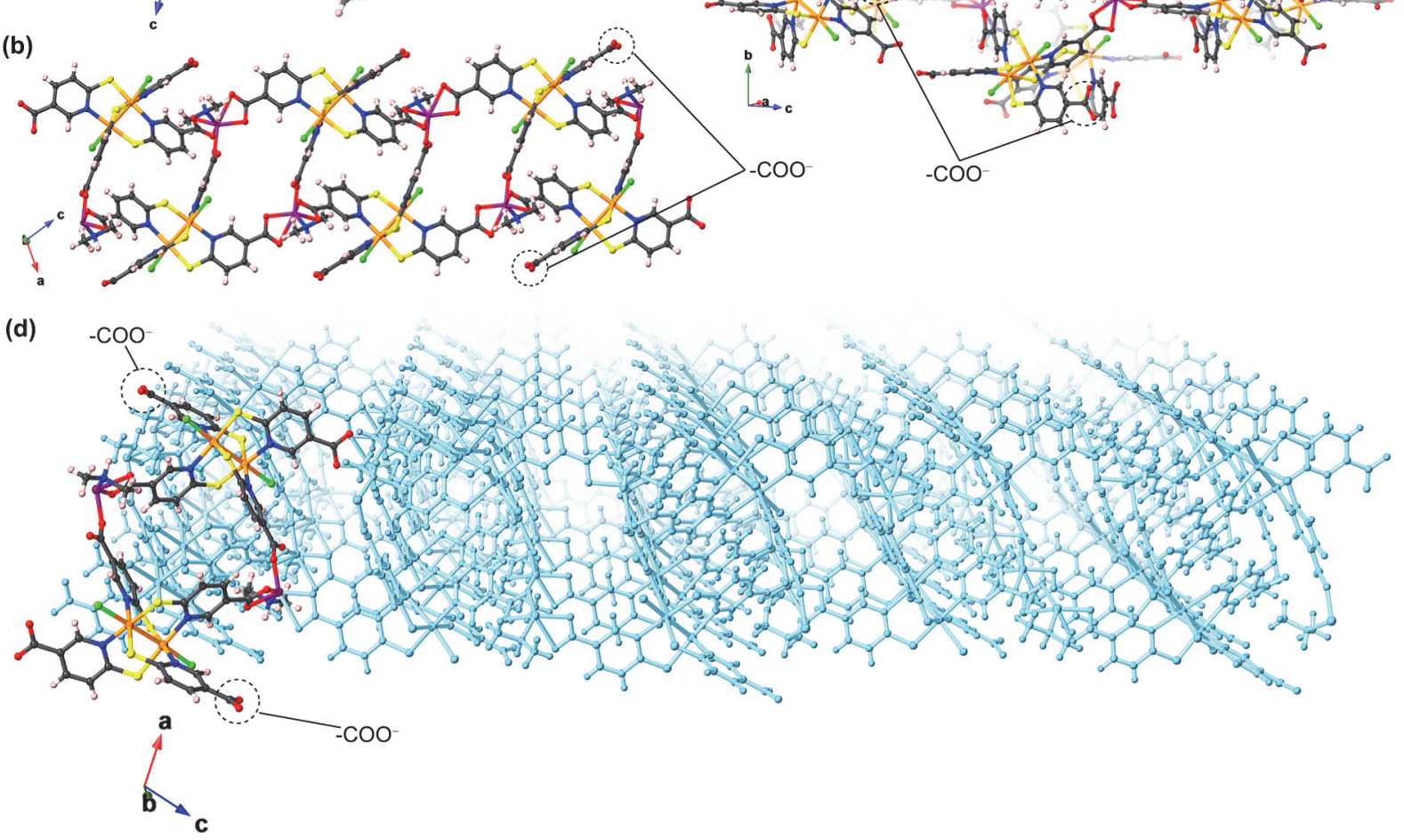

Figure S5. One 2D layer structure of 1 in different views. (a) A pair of Pt dimer units which forms "repeating unit" of 2D layer (see panel d). (b) and (c) 2D layer structure viewed along $b$ and $a$ axes. (d) Enlarged view of the 2D layer structure formed in 1, where three out of four carboxyl groups of the Pt dimer are used for coordination with a Co ion to form the 2D layer. In this panel, one pair of Pt dimer units is highlighted in original color (see panel a). For panels (b)-(d), the carboxyl groups $\left(-\mathrm{COO}^{-}\right)$of the MPC ligand that interact with $\mathrm{HDMA}^{+}$are also denoted for clarity. 


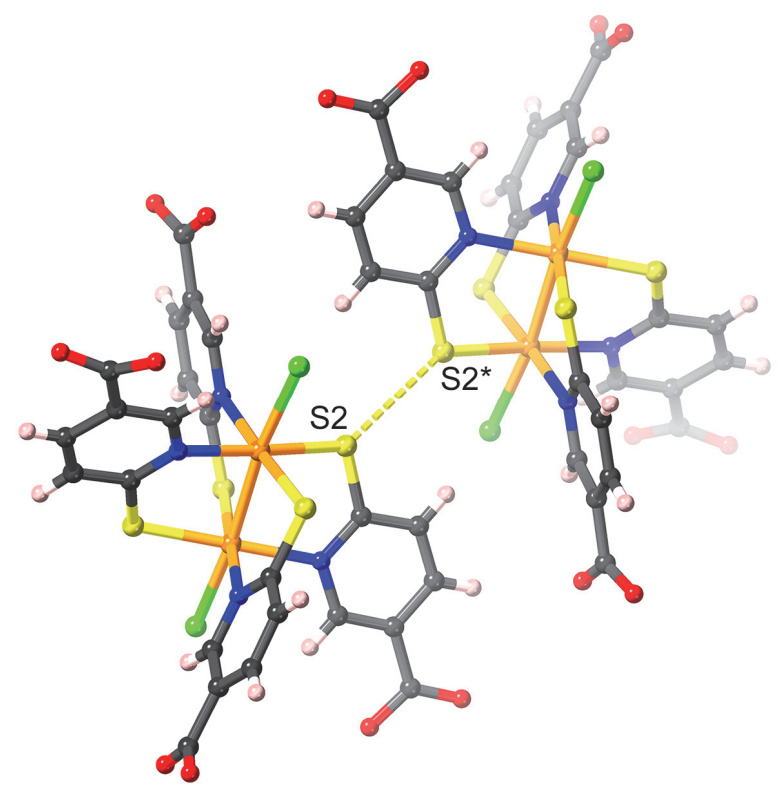

Figure S6. Enlarged view of the $\mathrm{S}-\mathrm{S}$ short contact in $\mathbf{1}$ (see Figure $2 \mathrm{~b}$ ). Note that the $\mathrm{S} 2 \cdots \mathrm{S} 2 *$ distance is $3.376(3) \AA$, which is significantly shorter than the sum of van der Waals $\operatorname{radii}(\sim 3.7 \AA)$.

(a)

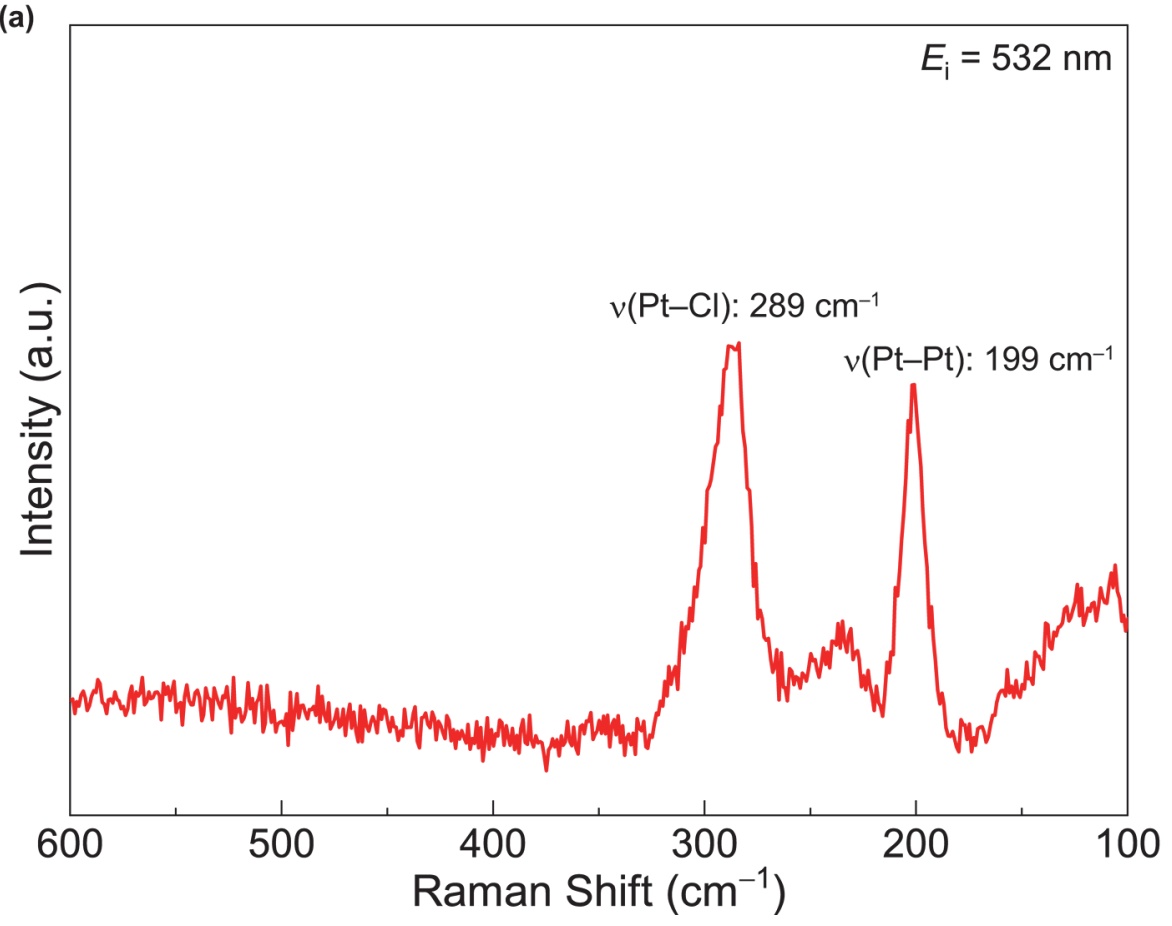

(b)
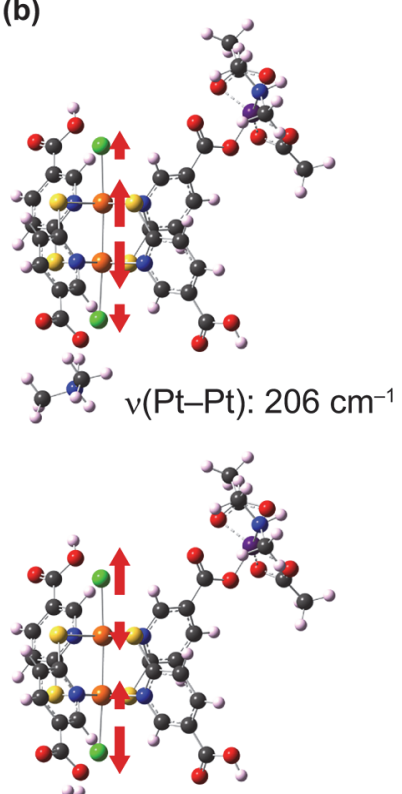

$v(\mathrm{Pt}-\mathrm{Cl}): 298 \mathrm{~cm}^{-1}$

Figure S7. (a) Raman spectrum of 1 at RT. (b) Corresponding vibration modes and their vibrational frequencies based on DFT calculation on the model structure of $\mathbf{1}$. 


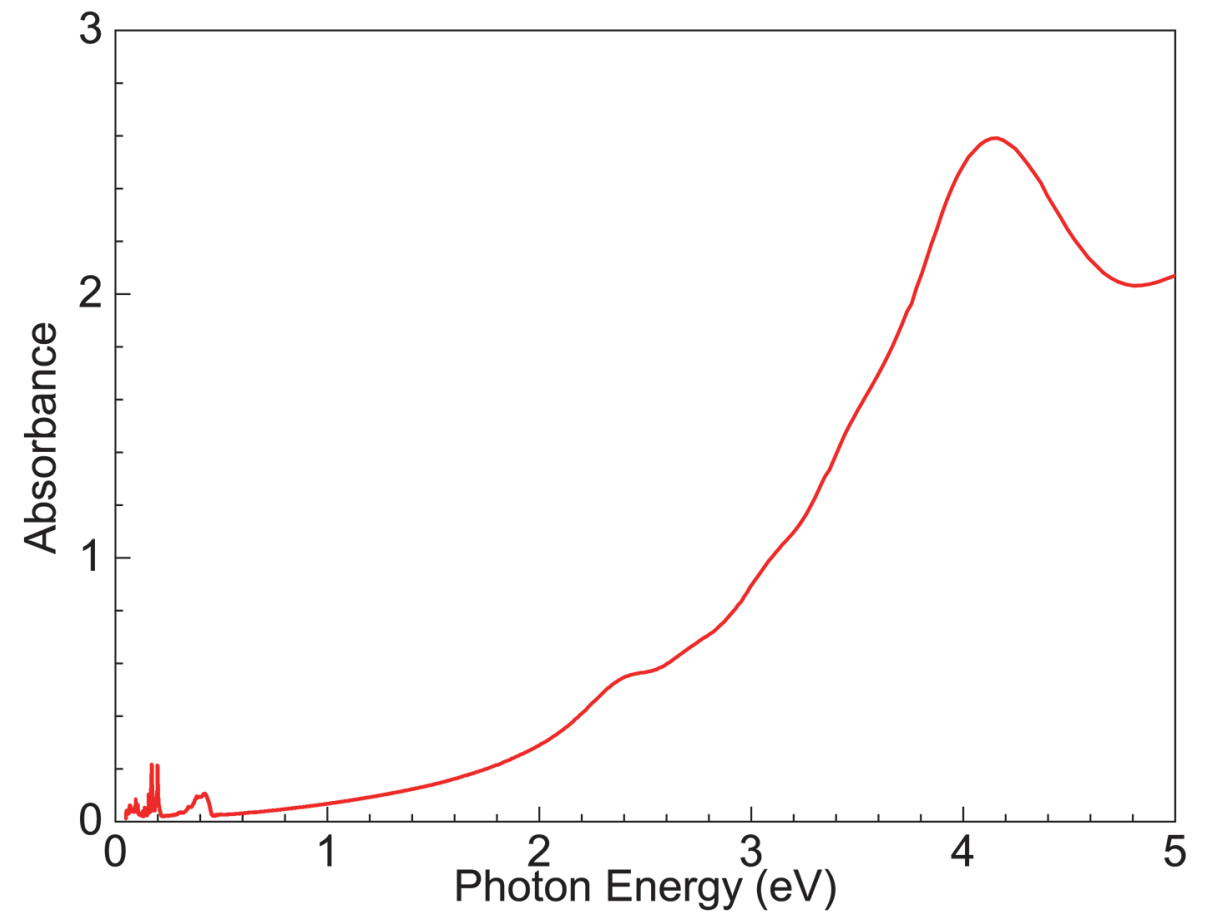

Figure S8. Electronic absorption spectrum of $\mathbf{1}$ at RT. 


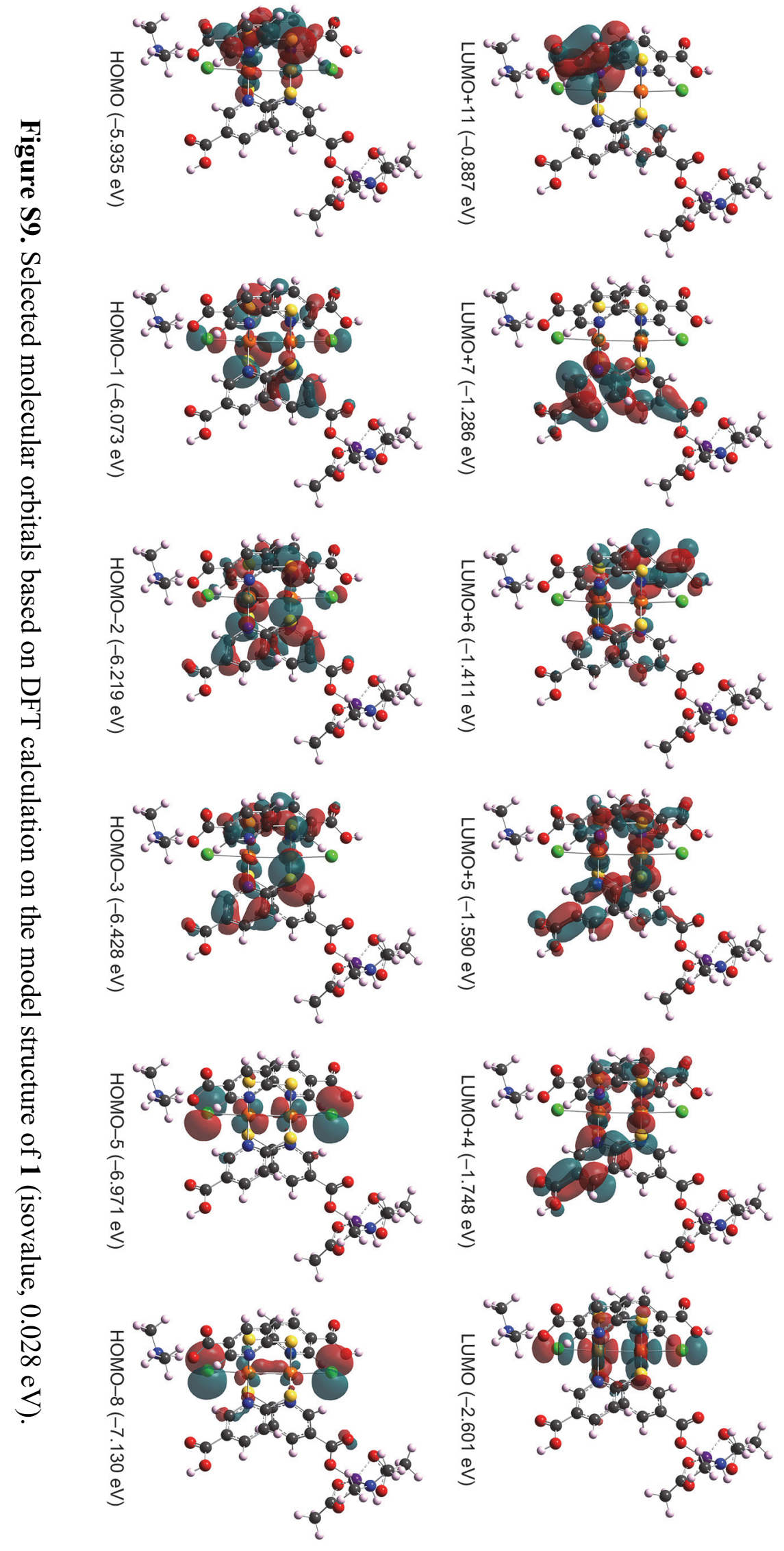


Table S1. Excitation energies $(\Delta E)$, oscillator strengths $(f)$, and assignments of excitation with relatively high probability based on the TDDFT calculation.

\begin{tabular}{ccc}
\hline $\boldsymbol{\Delta} \boldsymbol{E}(\mathrm{eV})$ & $\boldsymbol{f}$ & \multicolumn{1}{c}{ Assignment } \\
\hline 2.514 & 0.0048 & HOMO-1 $\rightarrow$ LUMO $(41 \%)\left(\mathrm{p} \sigma \rightarrow \mathrm{d} \sigma^{*}\right)$ \\
4.152 & 0.0528 & HOMO-3 $\rightarrow$ LUMO $+5(14 \%)\left(\mathrm{n} \rightarrow \pi^{*}\right)$ \\
4.152 & 0.0528 & HOMO-2 $\rightarrow$ LUMO+7 $(19 \%)(\mathrm{MLCT})$ \\
4.195 & 0.0518 & HOMO $\rightarrow$ LUMO+11 $(16 \%)\left(\mathrm{n} \rightarrow \pi^{*}\right)$ \\
4.312 & 0.0306 & HOMO-3 $\rightarrow$ LUMO+6 $(20 \%)(\mathrm{MLCT})$ \\
4.381 & 0.1032 & HOMO-5 $\rightarrow$ LUMO+4 $(18 \%)(\mathrm{MLCT})$ \\
4.519 & 0.0199 & HOMO-8 $\rightarrow$ LUMO+4 $(11 \%)(\mathrm{MLCT})$ \\
\hline
\end{tabular}


Table S2. Cartesian coordinates of the optimized structure of DFT calculation.

\begin{tabular}{|c|c|c|c|c|c|}
\hline \multirow{2}{*}{$\begin{array}{l}\text { Center } \\
\text { Number }\end{array}$} & \multirow{2}{*}{$\begin{array}{l}\text { Atomic } \\
\text { Number }\end{array}$} & \multirow{2}{*}{$\begin{array}{l}\text { Atomic } \\
\text { Type }\end{array}$} & \multicolumn{3}{|c|}{ Coordinates $(\AA)$} \\
\hline & & & $X$ & $\mathrm{Y}$ & Z \\
\hline 1 & 78 & 0 & -2.289570 & 0.311536 & -0.856286 \\
\hline 2 & 78 & 0 & -0.521993 & 1.251577 & 0.728976 \\
\hline 3 & 27 & 0 & 7.227091 & -1.493390 & 0.219576 \\
\hline 4 & 17 & 0 & -3.935138 & -0.434065 & -2.533934 \\
\hline 5 & 17 & 0 & 1.008996 & 2.166906 & 2.432183 \\
\hline 6 & 16 & 0 & -0.651442 & 0.027589 & -2.474966 \\
\hline 7 & 16 & 0 & -2.696704 & 2.457267 & -1.643652 \\
\hline 8 & 16 & 0 & -2.191082 & 2.393734 & 1.876913 \\
\hline 9 & 16 & 0 & -0.823787 & -0.583471 & 2.115279 \\
\hline 10 & 8 & 0 & 5.405624 & -1.497760 & -0.188168 \\
\hline 11 & 8 & 0 & 4.646717 & -0.295444 & 1.569438 \\
\hline 12 & 8 & 0 & 9.115842 & -1.124781 & 0.495253 \\
\hline 13 & 8 & 0 & 7.569197 & 0.378325 & 0.525524 \\
\hline 14 & 8 & 0 & -7.190508 & -1.658704 & 0.294542 \\
\hline 15 & 8 & 0 & -8.219467 & -0.520685 & 1.942260 \\
\hline 16 & 8 & 0 & 7.381218 & -3.275866 & -0.462899 \\
\hline 17 & 8 & 0 & -2.963753 & -4.903001 & -2.537407 \\
\hline 18 & 8 & 0 & 7.549047 & -1.522756 & -1.713885 \\
\hline 19 & 7 & 0 & 1.008664 & 0.232530 & -0.320938 \\
\hline 20 & 7 & 0 & -0.261975 & 2.925715 & -0.530285 \\
\hline 21 & 7 & 0 & -3.784524 & 0.582731 & 0.620435 \\
\hline 22 & 7 & 0 & -1.930845 & -1.644341 & -0.133695 \\
\hline 23 & 7 & 0 & 7.126522 & -2.057115 & 2.087718 \\
\hline 24 & 1 & 0 & 8.001151 & -2.581995 & 2.118361 \\
\hline 25 & 7 & 0 & -9.544630 & -2.783462 & 0.117760 \\
\hline 26 & 1 & 0 & -9.586520 & -3.498665 & -0.602127 \\
\hline 27 & 1 & 0 & -8.111063 & -2.134293 & 0.215459 \\
\hline 28 & 6 & 0 & 0.840106 & -0.171082 & -1.602655 \\
\hline 29 & 6 & 0 & 1.908938 & -0.770258 & -2.294945 \\
\hline 30 & 1 & 0 & 1.747052 & -1.081622 & -3.321463 \\
\hline 31 & 6 & 0 & 3.115142 & -0.975020 & -1.662893 \\
\hline 32 & 1 & 0 & 3.952144 & -1.437672 & -2.175194 \\
\hline 33 & 6 & 0 & 3.259897 & -0.590273 & -0.325112 \\
\hline 34 & 6 & 0 & 2.182239 & 0.009159 & 0.302321 \\
\hline 35 & 1 & 0 & 2.260249 & 0.348913 & 1.330379 \\
\hline 36 & 6 & 0 & 4.531478 & -0.778859 & 0.448087 \\
\hline 37 & 6 & 0 & -1.237866 & 3.343902 & -1.372123 \\
\hline 38 & 6 & 0 & 1.100613 & 4.797946 & -1.126086 \\
\hline 39 & 6 & 0 & 0.883012 & 3.623834 & -0.427630 \\
\hline 40 & 1 & 0 & 1.615744 & 3.234425 & 0.270347 \\
\hline 41 & 6 & 0 & 8.809690 & 0.113745 & 0.550782 \\
\hline 42 & 6 & 0 & 2.360357 & 5.560947 & -1.010943 \\
\hline 43 & 6 & 0 & -3.647620 & 1.493490 & 1.612491 \\
\hline 44 & 6 & 0 & -4.721205 & 1.739334 & 2.491740 \\
\hline 45 & 1 & 0 & -4.586200 & 2.476159 & 3.276170 \\
\hline 46 & 6 & 0 & -5.891079 & 1.028597 & 2.367003 \\
\hline 47 & 1 & 0 & -6.734572 & 1.188479 & 3.031494 \\
\hline 48 & 6 & 0 & -5.994984 & 0.050764 & 1.369471 \\
\hline
\end{tabular}




\begin{tabular}{|c|c|c|c|c|c|}
\hline 49 & 6 & 0 & -4.921748 & -0.131146 & 0.516917 \\
\hline 50 & 1 & 0 & -4.972464 & -0.835229 & -0.305665 \\
\hline 51 & 6 & 0 & -7.248371 & -0.739334 & 1.231422 \\
\hline 52 & 6 & 0 & -1.404081 & -1.858073 & 1.097909 \\
\hline 53 & 6 & 0 & -1.311963 & -3.173317 & 1.600148 \\
\hline 54 & 1 & 0 & -0.900107 & -3.317377 & 2.593095 \\
\hline 55 & 6 & 0 & -1.702790 & -4.239186 & 0.826087 \\
\hline 56 & 1 & 0 & -1.626140 & -5.255676 & 1.197259 \\
\hline 57 & 6 & 0 & -2.178362 & -3.999907 & -0.472213 \\
\hline 58 & 6 & 0 & -2.276407 & -2.688286 & -0.906025 \\
\hline 59 & 1 & 0 & -2.668365 & -2.452339 & -1.891181 \\
\hline 60 & 6 & 0 & 7.559287 & -2.785051 & -1.630677 \\
\hline 61 & 6 & 0 & -2.582739 & -5.074072 & -1.402456 \\
\hline 62 & 6 & 0 & 7.182456 & -1.016208 & 3.129418 \\
\hline 63 & 1 & 0 & 8.105894 & -0.445459 & 3.031011 \\
\hline 64 & 1 & 0 & 7.160233 & -1.483921 & 4.120626 \\
\hline 65 & 1 & 0 & 6.321010 & -0.361934 & 2.996177 \\
\hline 66 & 6 & 0 & 6.025007 & -3.005022 & 2.337234 \\
\hline 67 & 1 & 0 & 5.967435 & -3.716108 & 1.512841 \\
\hline 68 & 1 & 0 & 5.097578 & -2.437992 & 2.407708 \\
\hline 69 & 1 & 0 & 6.201264 & -3.538194 & 3.278787 \\
\hline 70 & 6 & 0 & -9.839534 & -3.375382 & 1.420184 \\
\hline 71 & 1 & 0 & -9.170552 & -4.221582 & 1.597643 \\
\hline 72 & 1 & 0 & -10.879754 & -3.721571 & 1.503039 \\
\hline 73 & 1 & 0 & -9.652394 & -2.618694 & 2.186977 \\
\hline 74 & 6 & 0 & -10.458953 & -1.694474 & -0.219667 \\
\hline 75 & 1 & 0 & -10.225735 & -1.317557 & -1.218772 \\
\hline 76 & 1 & 0 & -10.305742 & -0.886032 & 0.500249 \\
\hline 77 & 1 & 0 & -11.513766 & -2.003103 & -0.192380 \\
\hline 78 & 6 & 0 & -1.080114 & 4.553792 & -2.080967 \\
\hline 79 & 6 & 0 & 0.078014 & 5.280161 & -1.956366 \\
\hline 80 & 8 & 0 & 2.567823 & 6.613340 & -1.574183 \\
\hline 81 & 1 & 0 & -1.878709 & 4.870800 & -2.742725 \\
\hline 82 & 1 & 0 & 0.233562 & 6.207947 & -2.498036 \\
\hline 83 & 8 & 0 & 3.261311 & 4.963905 & -0.215875 \\
\hline 84 & 1 & 0 & 4.035972 & 5.543249 & -0.198055 \\
\hline 85 & 8 & 0 & -2.478715 & -6.297239 & -0.845545 \\
\hline 86 & 1 & 0 & -2.759499 & -6.920773 & -1.530572 \\
\hline 87 & 6 & 0 & 7.737896 & -3.664603 & -2.819981 \\
\hline 88 & 1 & 0 & 8.361364 & -4.522332 & -2.560366 \\
\hline 89 & 1 & 0 & 6.757537 & -4.041338 & -3.128342 \\
\hline 90 & 1 & 0 & 8.177728 & -3.101925 & -3.643712 \\
\hline 91 & 6 & 0 & 9.847259 & 1.180614 & 0.608261 \\
\hline 92 & 1 & 0 & 10.106607 & 1.465151 & -0.416638 \\
\hline 93 & 1 & 0 & 9.455805 & 2.060498 & 1.120625 \\
\hline 94 & 1 & 0 & 10.747759 & 0.808785 & 1.099357 \\
\hline
\end{tabular}


(a)

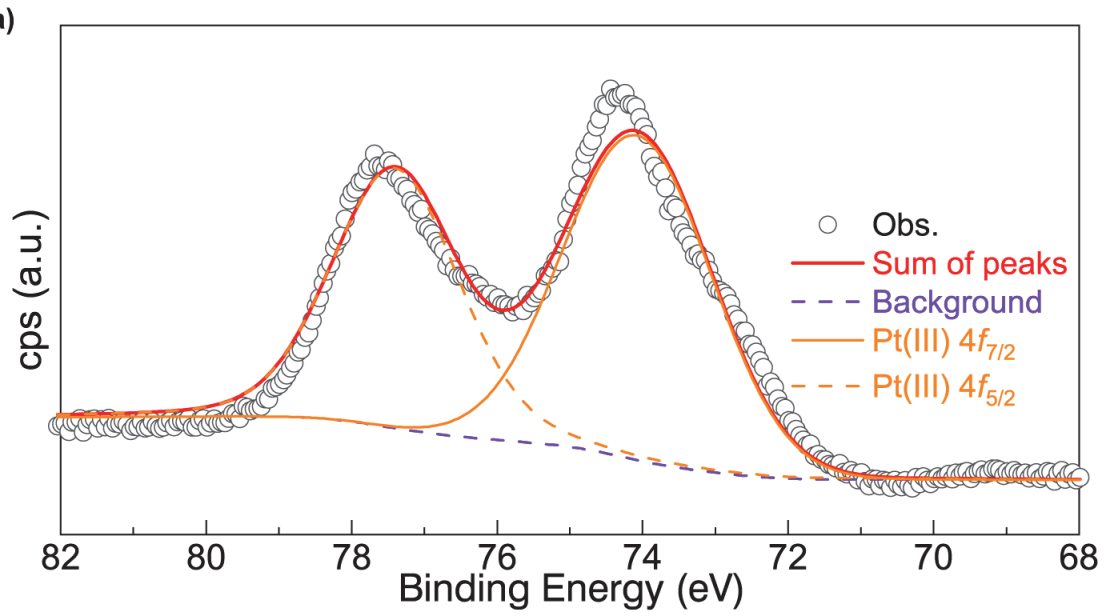

(b)

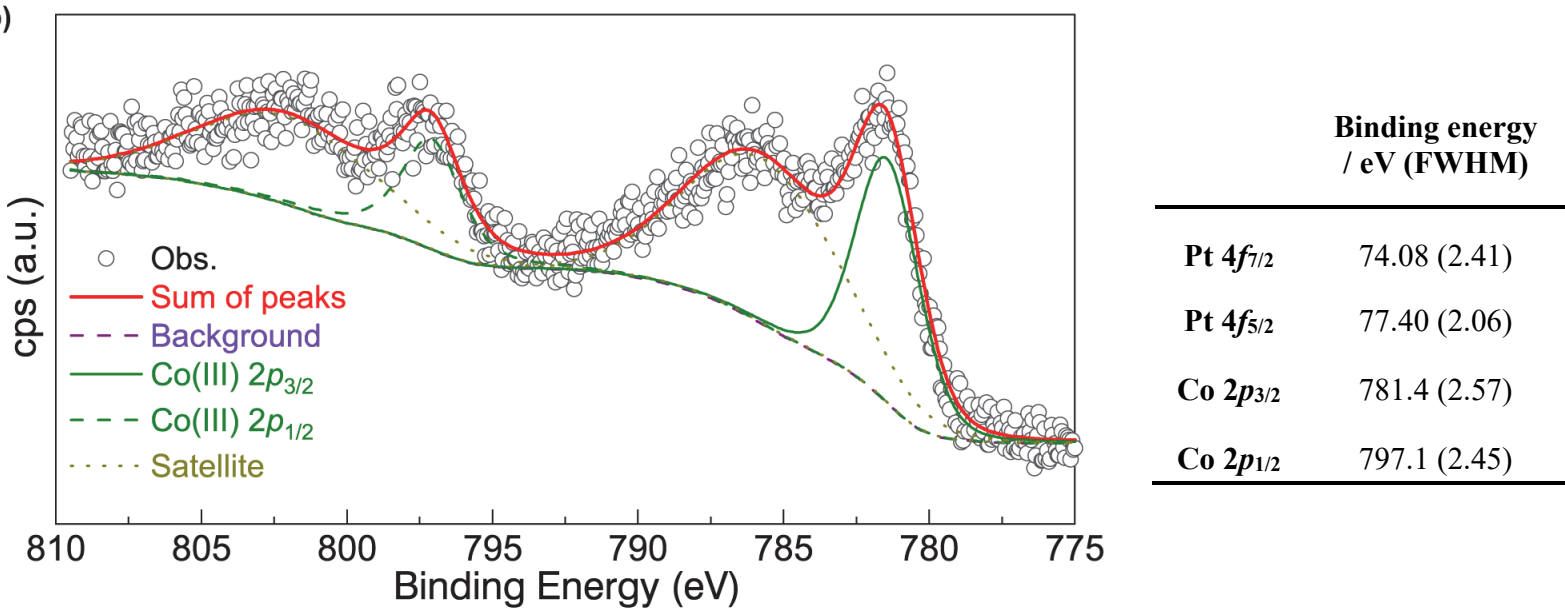

Figure S10. XPS spectra of Pt $4 f$ (a) and Co $2 p$ (b) for 1 at RT. Peak position and FWHM obtained from the fitting analysis are also shown on the right. The results are consistent with the results on the trivalent states. 


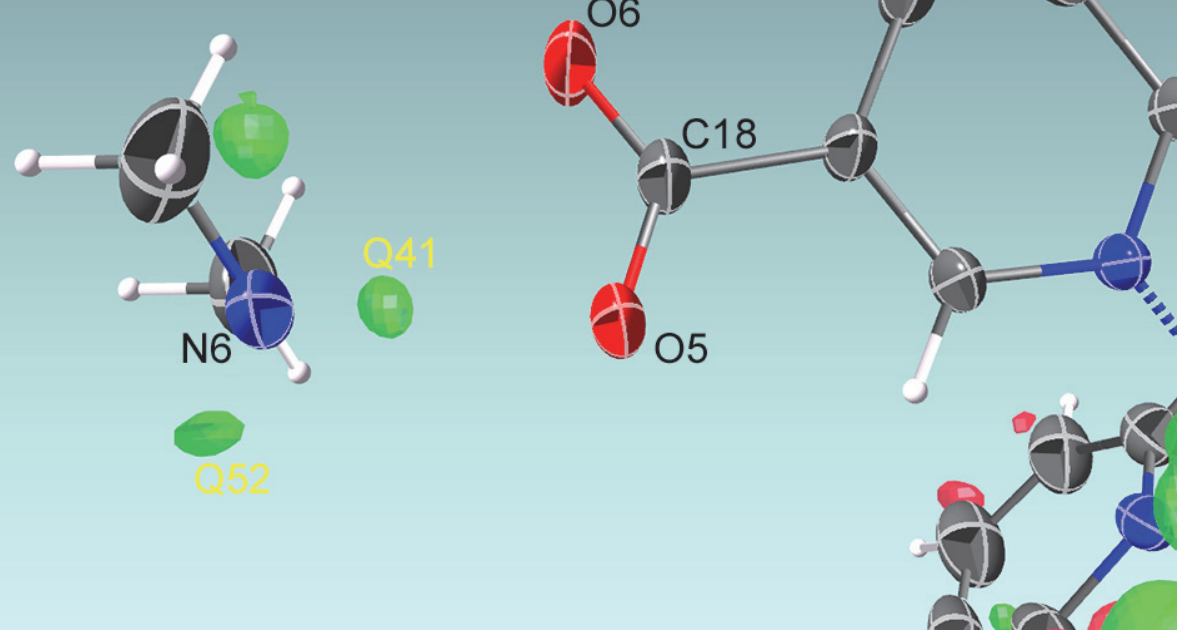

Figure S11. $F_{\mathrm{o}}-F_{\mathrm{c}}$ map $\left(0.50 \mathrm{e} \AA^{-3}\right)$ around $\mathrm{MPC}-\mathrm{HDMA}^{+}$pair calculated from the crystal structure without H6A and H6B sites using ShelXle software. ${ }^{11}$ Clear positive peaks (shown in a green cloud), Q41 $\left(0.68 \mathrm{e}^{-3}\right)$ and Q52 $\left(0.57 \mathrm{e}^{-3}\right)$ corresponding to $\mathrm{H}$ atom were observed close to the N6 site.

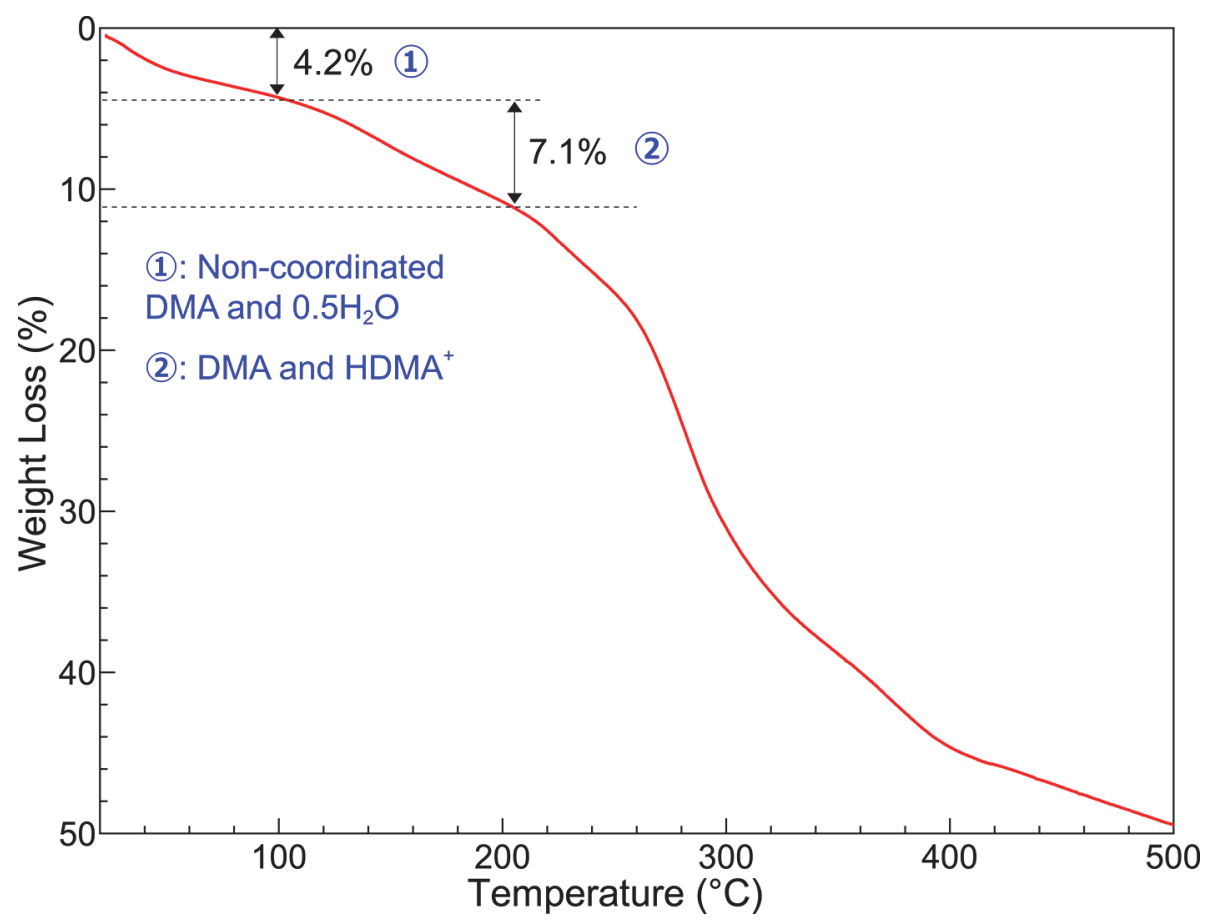

Figure S12. TGA curve of 1. 
(a)

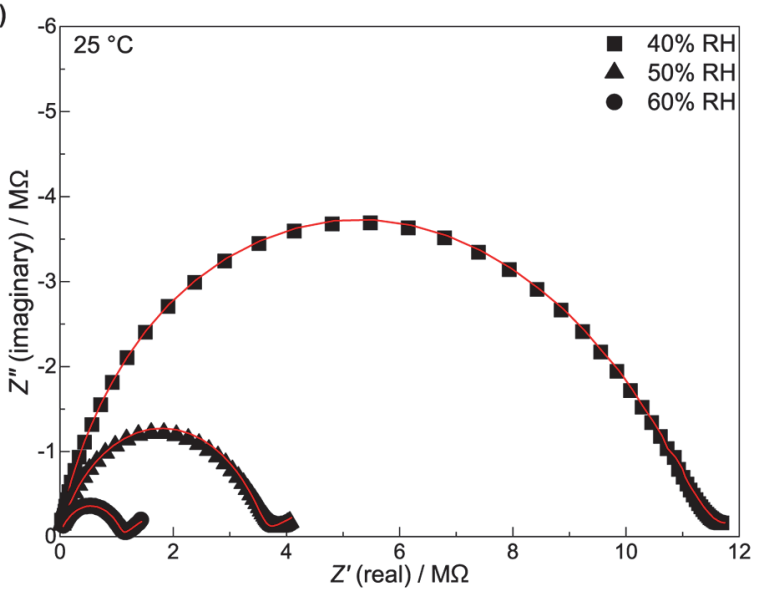

(c)

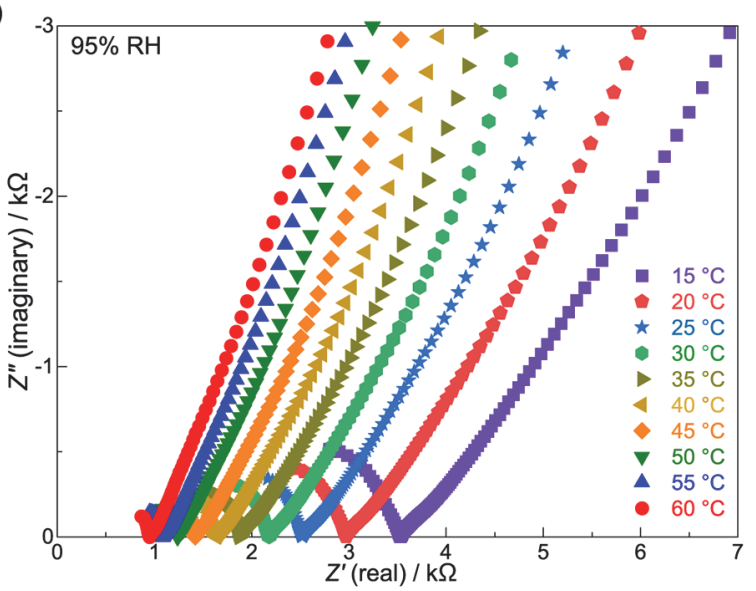

(b)

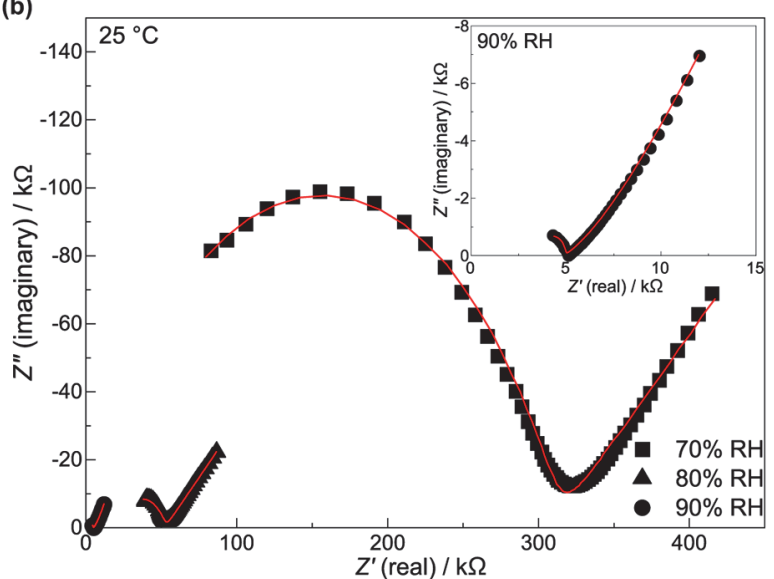

(d)

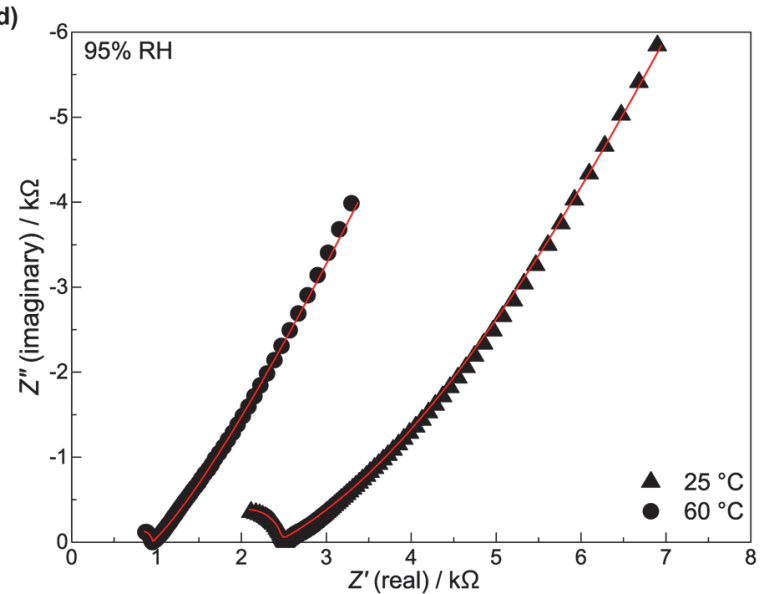

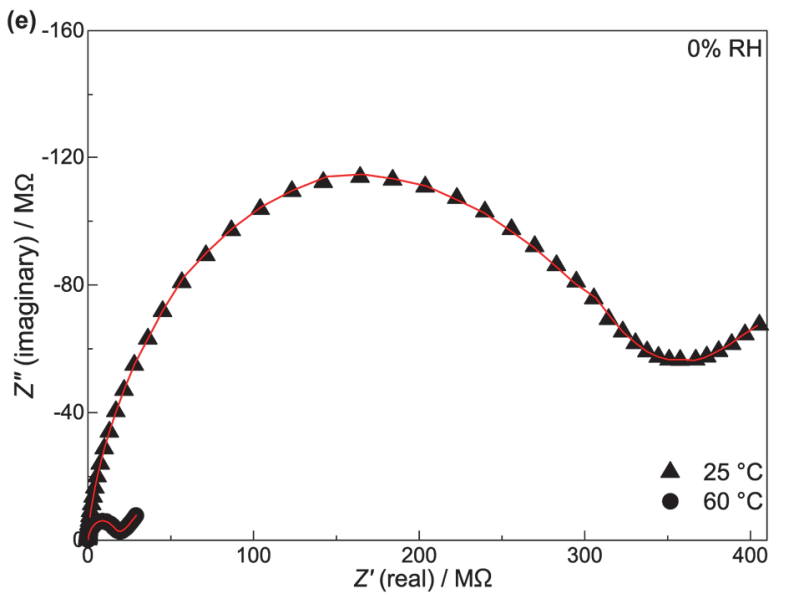

Figure S13. Selected Nyquist plots measured with pelletized polycrystalline powder of 1. (a), (b) Humidity dependence of the Nyquist plots at $25{ }^{\circ} \mathrm{C}$. (c), (d) Temperature dependence of the Nyquist plots at 95\% RH. (e) Temperature dependence of the Nyquist plots at $0 \% \mathrm{RH}$. Red solid lines denote the fitting result. 


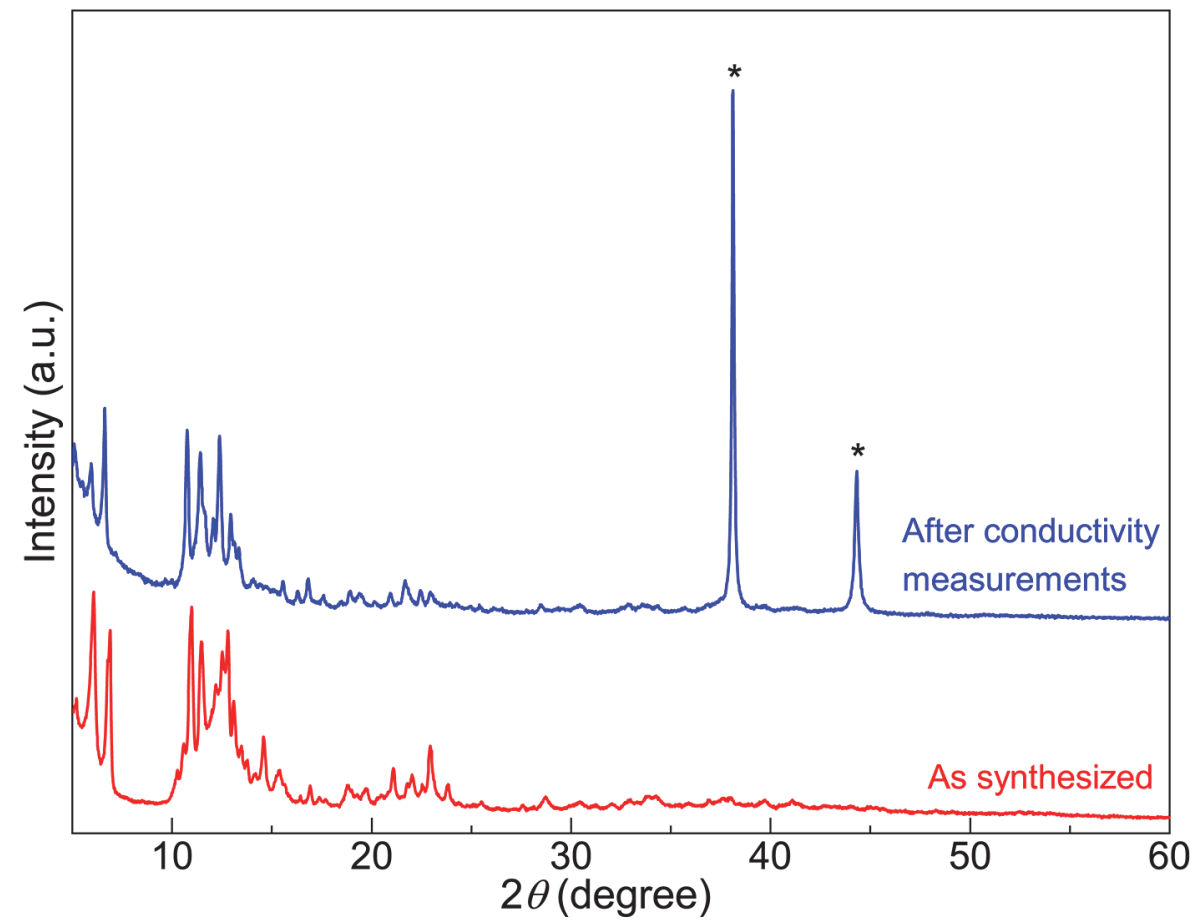

Figure S14. PXRD patterns of as-synthesized 1 (red) and 1 after proton conductivity measurements (blue). The asterisks (*) denote the diffraction peaks from Au (paste for electrodes). The result clearly showed that the crystallinity of 1 retains under high humidity conditions. 
(a)

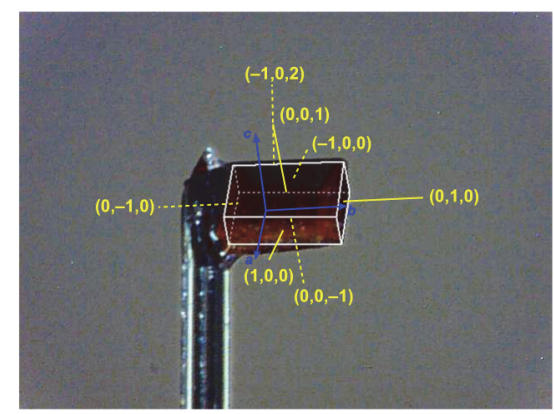

(c)

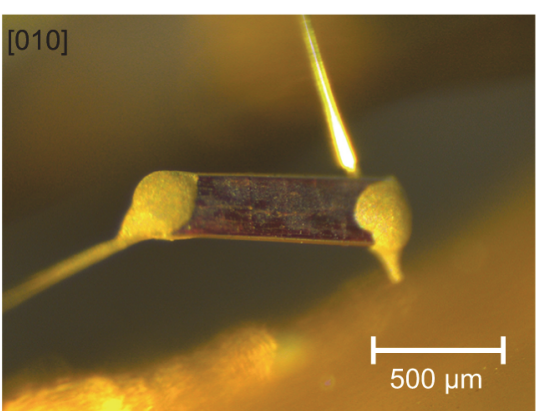

(b)

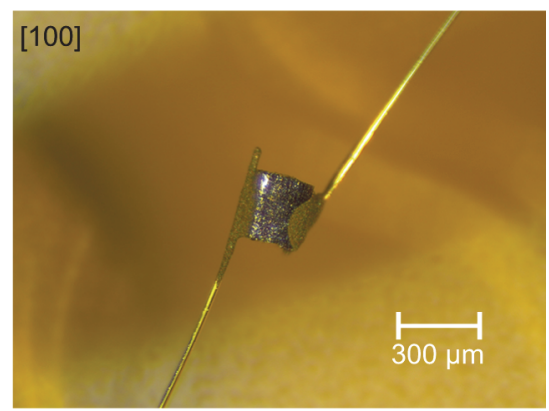

(d)

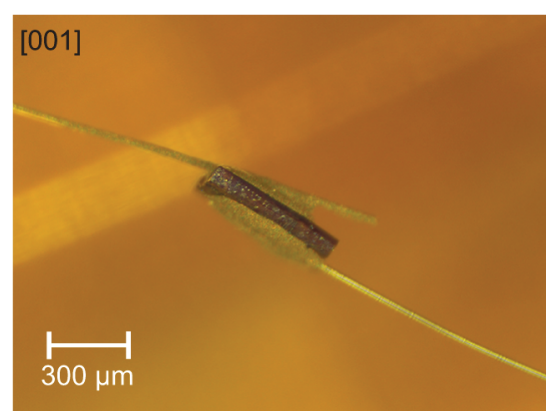

Figure S15. Experimental setup for single-crystal proton conductivity measurement on 1. (a) Crystal-face indices determined from XRD (CrysAlis ${ }^{\text {Pro }}$ software $^{12}$ installed on Rigaku XtaLAB P-200 X-ray diffractometer). (b)-(d) Electrical contacts made along the [100], [010], and [001] directions. 
(a)

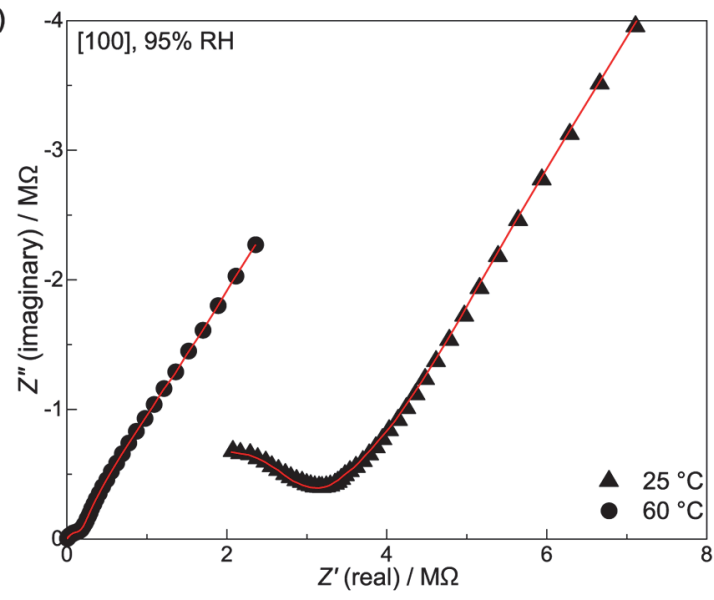

(c)

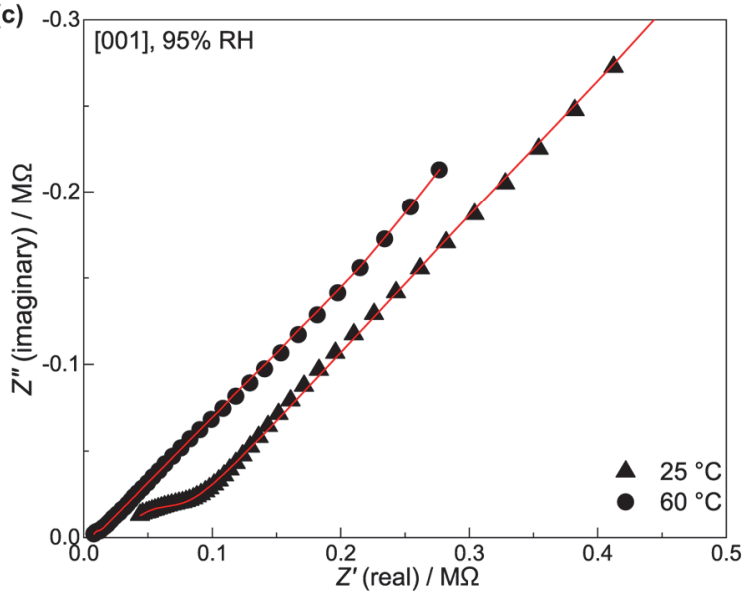

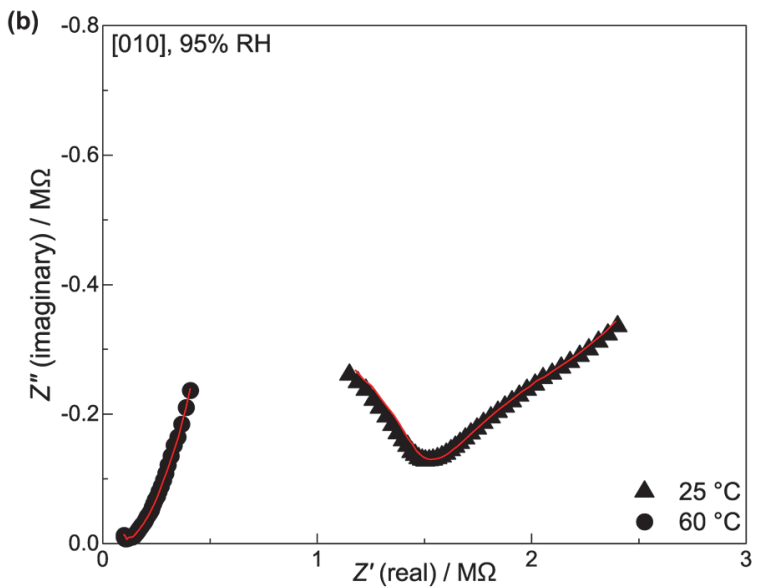

(d)

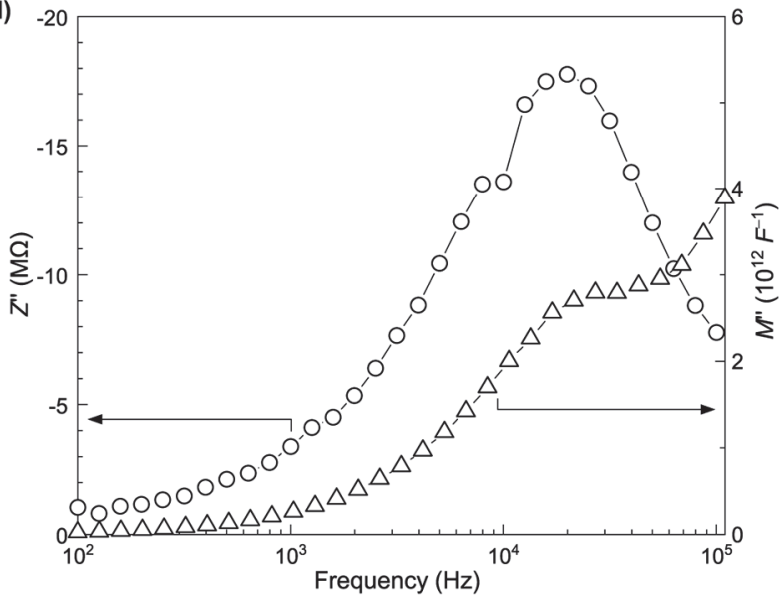

Figure S16. Selected results of single-crystal proton conductivity measurement on 1. (a)-(c) Temperature dependence of the Nyquist plots at 95\% RH along the [100], [010], and [001] directions. Red solid lines denote the fitting result. (d) Impedance ( $\left.Z^{\prime}\right)$ and modulus ( $M$ ') spectra $\left(75 \% \mathrm{RH}\right.$ and $\left.25^{\circ} \mathrm{C}\right)$. 


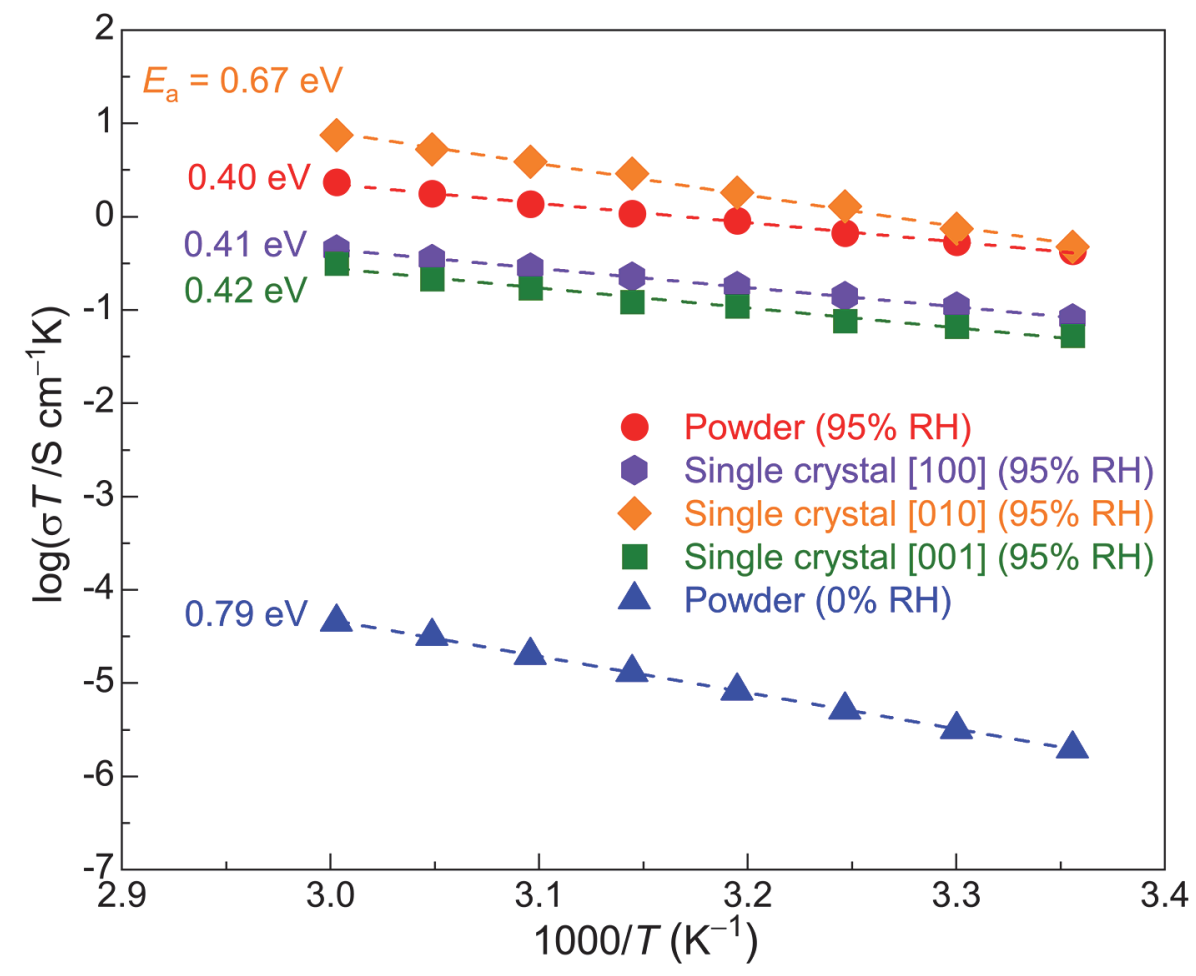

Figure S17. Arrhenius plots of the proton conductivity of 1 measured with pelletized polycrystalline powder and single crystal.

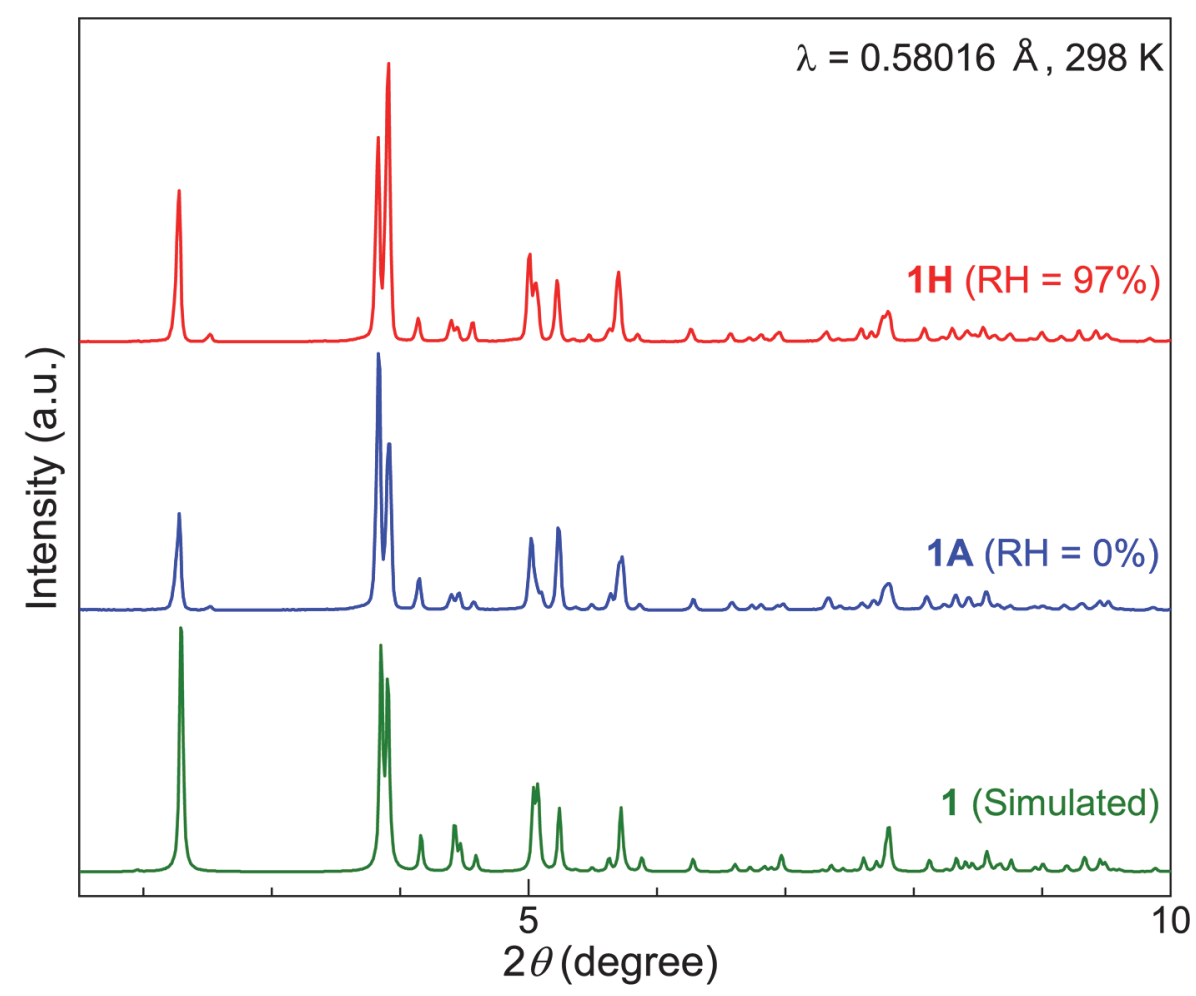

Figure S18. PXRD patterns of $\mathbf{1 A}$ and $\mathbf{1 H}$. The simulated pattern of $\mathbf{1}$ is also shown. 


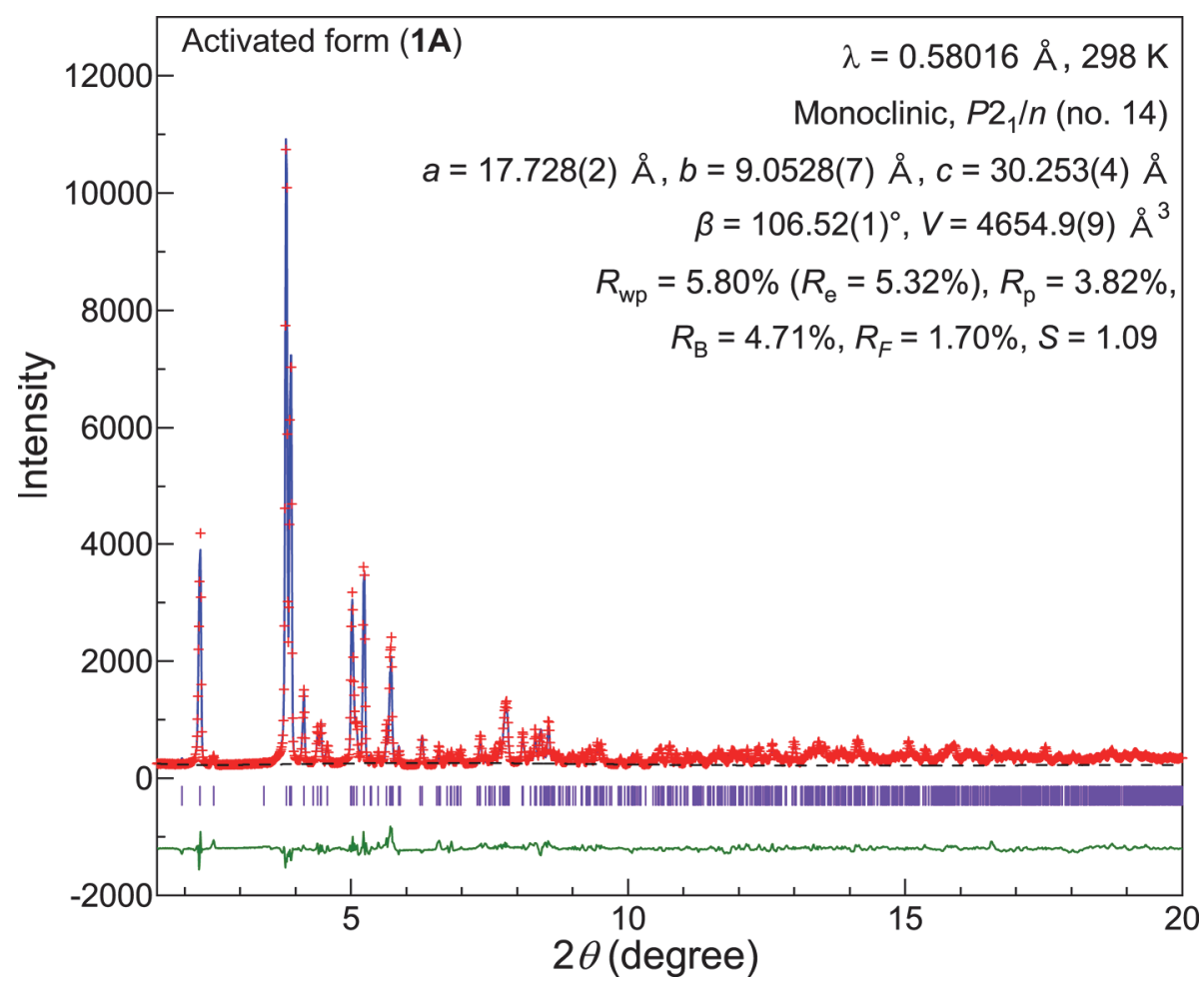

Figure S19. Rietveld fitting result of 1A. Red crosses, blue line, green line, black dotted line, and purple ticks denote the experimental, calculated, difference, background profiles, and positions of Bragg peaks, respectively.

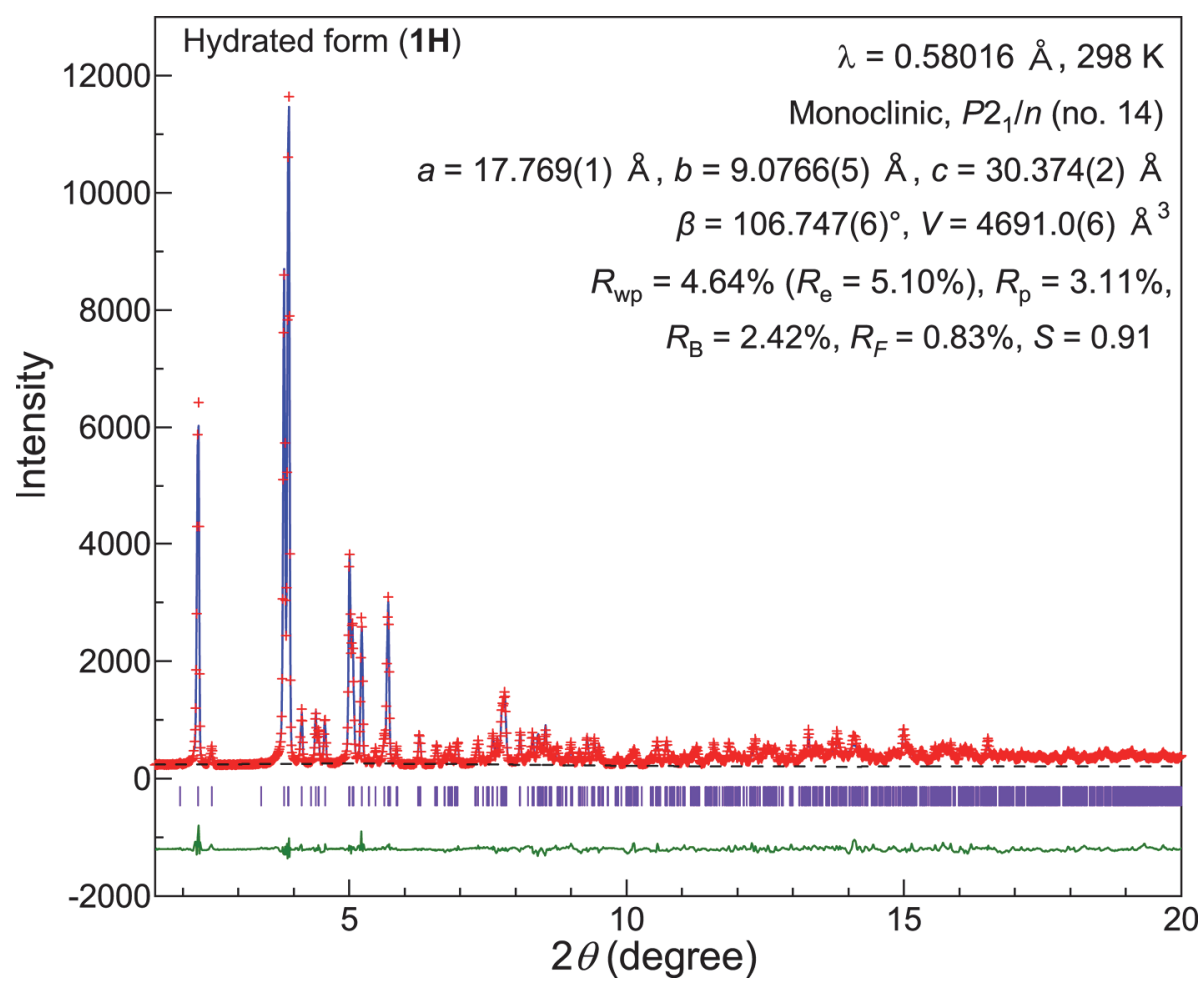

Figure S20. As Figure S17, but for $\mathbf{1 H}$. 


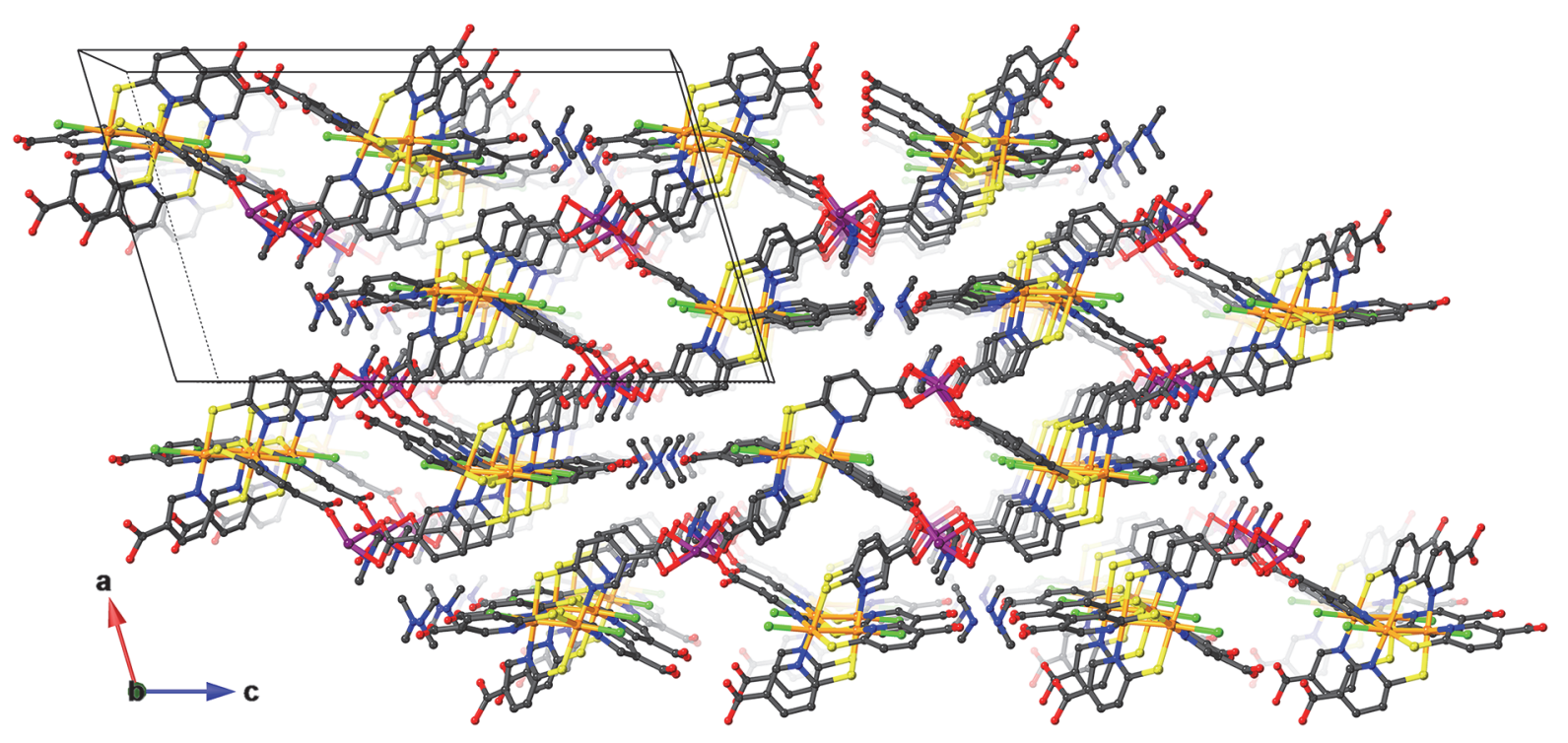

Figure S21. 3D packing structure of 1A along the $b$-axis. Color code as in Figure 2.

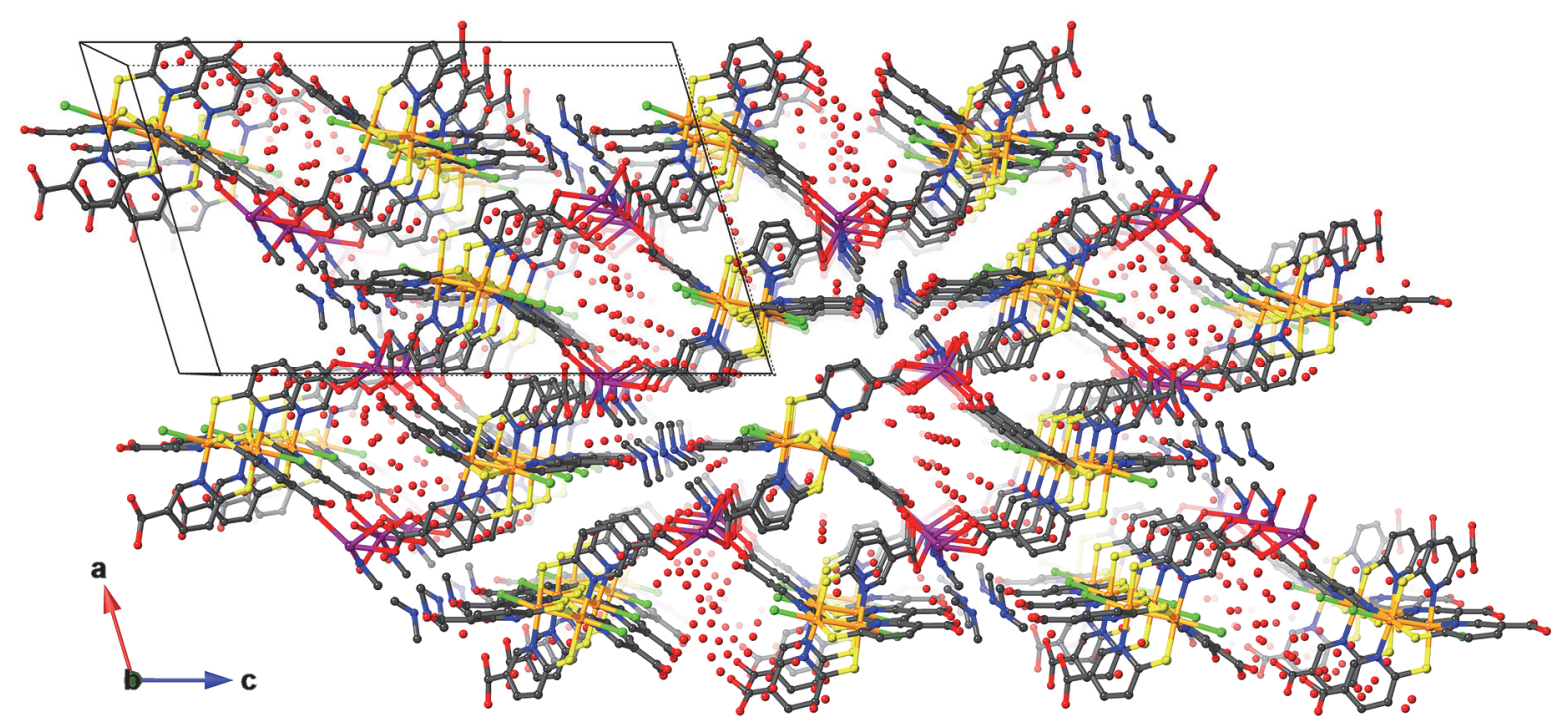

Figure S22. 3D packing structure of $\mathbf{1 H}$ along the $b$-axis. Isolated $\mathrm{O}$ atoms denote crystallization $\mathrm{H}_{2} \mathrm{O}$ molecules found in the structural analysis. Color code as in Figure 2. 
(a)

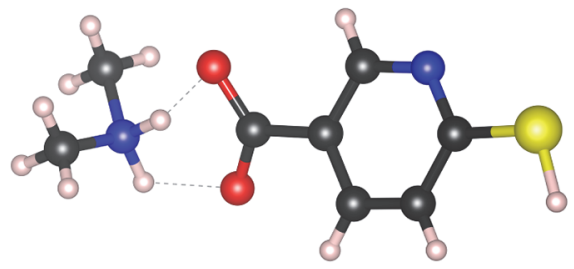

(b)

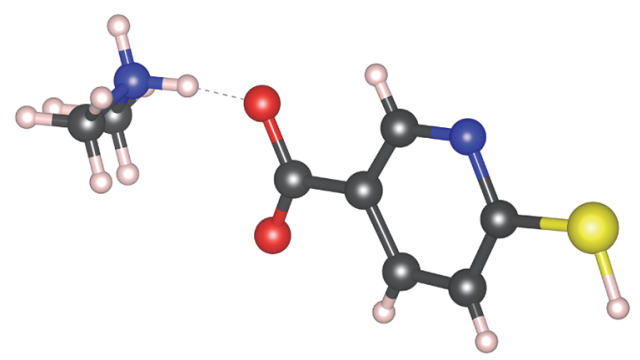

(c)

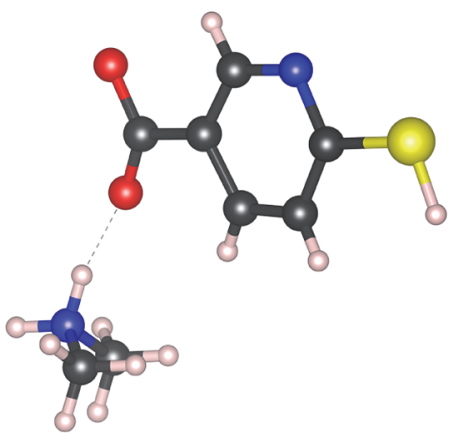

Figure S23. Model HMPC-HDMA ${ }^{+}$pairs adopted from the X-ray crystal structures for the counterpoise calculation. (a) 1A. (b) $\mathbf{1 H}$ (type A), and (c) $\mathbf{1 H}$ (type B).

Table S3. Summary of the intermolecular complexation energies on model structures based on the counterpoise calculation. The subscripts 1 and 2 denote the structures with (1) and without (2) hydrogen bonds, respectively.

\begin{tabular}{ccccc}
\hline Model & $\boldsymbol{E}_{\mathrm{cp}}(\mathbf{k J} / \mathbf{m o l})$ & $\boldsymbol{E}_{\text {pair }}($ Hartree $)$ & $\boldsymbol{E}_{\text {monomers }}($ Hartree $)$ & $\boldsymbol{\Delta E}_{\text {BSSE }}($ Hartree $)$ \\
\hline $\mathbf{1 A}_{\mathbf{1}}$ & -450.3285481 & -969.2579994 & -969.0864778 & 0.000980224 \\
$\mathbf{1 A}_{\mathbf{2}}$ & -387.1494988 & -969.234092 & -969.0866406 & 0.001290632 \\
$\mathbf{1 H}($ type A) & -443.0901537 & -969.3929726 & -969.224217 & 0.000673757 \\
$\mathbf{1 H}($ type B) & -383.3420197 & -969.3701395 & -969.2241315 & 0.000683178 \\
$\mathbf{1 H}($ type A) & -425.5171731 & -969.3865733 & -969.2245009 & 0.000743518 \\
$\mathbf{1 H}($ type B) & -369.1999543 & -969.3650128 & -969.2244 & 0.000597737 \\
\hline
\end{tabular}

Table S4. Summary of the hydrogen-bonding energies in $\mathbf{1 A}$ and $\mathbf{1 H}$.

\begin{tabular}{cccc}
\hline Model & $\boldsymbol{\Delta} E_{\mathrm{H}}(\mathrm{kJ} / \mathbf{m o l})$ & $\boldsymbol{\Delta} E_{\mathrm{HA}}(\mathrm{kJ} / \mathbf{m o l})$ & $\boldsymbol{\Delta} E_{\mathrm{HB}}(\mathrm{kJ} / \mathbf{m o l})$ \\
\hline $\mathbf{1 A}$ & 63.2 & - & - \\
$\mathbf{1 H}$ & 31.7 & 17.6 & 14.1 \\
\hline
\end{tabular}




\section{References}

(1) Burla, M. C.; Caliandro, R.; Camalli, M.; Carrozzini, B.; Cascarano, G. L.; De Caro, L.; Giacovazzo, C.; Polidori, G.; Spagna R. SIR2004: an improved tool for crystal structure determination and refinement. J. Appl. Cryst. 2005, 38, 381-388.

(2). Sheldrick, G.M. Crystal structure refinement with SHELXL. Acta Crystallogr. Sect. C Struct. Chem. 2015, 71, 3-8.

(3). CrystalStructure 4.3: Crystal Structure Analysis Package, Rigaku Corporation (2000-2019).

(4) Altomare, A.; Cuocci, C.; Giacovazzo, C.; Moliterni, A.; Rizzi, R.; Corriero, N.; Falcicchio, A. EXPO2013: a kit of tools for phasing crystal structures from powder data. $J$. Appl. Crystallogr. 2013, 46, 1231-1235.

(5) Izumi, F.; Momma, K. Three-Dimensional Visualization in Powder Diffraction. Solid State Phenom. 2007, 130, 15-20.

(6) Momma, K.; Ikeda, T.; Belik, A. A.; Izumi, F. Dysnomia, a computer program for maximum-entropy method (MEM) analysis and its performance in the MEM-based pattern fitting. Powder Diffr., 2013, 28, 184-193.

(7) Momma, K.; Izumi, F. VESTA: a three-dimensional visualization system for electronic and structural analysis. J. Appl. Crystallogr. 2008, 41, 653-658.

(8) Frisch, M. J.; Trucks, G. W.; Schlegel, H. B.; Scuseria, G. E.; Robb, M. A.; Cheeseman, J. R.; Scalmani, G.; Barone, V.; Mennucci, B.; Petersson, G. A.; Nakatsuji, H.; Caricato, M.; Li, X.; Hratchian, H. P.; Izmaylov, A. F.; Bloino, J.; Zheng, G.; Sonnenberg, J. L.; Hada, M.; Ehara, M.; Toyota, K.; Fukuda, R.; Hasegawa, J.; Ishida, M.; Nakajima, T.; Honda, Y.; Kitao, O.; Nakai, H.; Vreven, T.; Montgomery, Jr., J. A.; Peralta, J. E.; Ogliaro, F.; Bearpark, M.; Heyd, J. J.; Brothers, E.; Kudin, K. N.; Staroverov, V. N.; Keith, T.; Kobayashi, R.; Normand, J.; Raghavachari, K.; Rendell, A.; Burant, J. C.; Iyengar, S. S.; Tomasi, J.; Cossi, M.; Rega, N.; Millam, J. M.; Klene, M.; Knox, J. E.; Cross, J. B.; Bakken, V.; Adamo, C.; Jaramillo, J.; Gomperts, R.; Stratmann, R. E.; Yazyev, O.; Austin, A. J.; Cammi, R.; Pomelli, C.; Ochterski, 
J. W.; Martin, R. L.; Morokuma, K.; Zakrzewski, V. G.; Voth, G. A.; Salvador, P.; Dannenberg, J. J.; Dapprich, S.; Daniels, A. D.; Farkas, O.; Foresman, J. B.; Ortiz, J. V.; Cioslowski, J.; Fox, D. J. Gaussian 09, Revision D.01. Gaussian, Inc., Wallingford CT, 2013.

(9) Mitsumi, M.; Ueda, H.; Furukawa, K.; Ozawa, Y.; Toriumi, K.; Kurmoo, M. Constructing Highly Conducting Metal-Metal Bonded Solids by Electrocrystallization of $\left[\mathrm{Pt}^{\mathrm{II}} 2\left(\mathrm{RCS}_{2}\right)_{4}\right]$ $\left(\mathrm{RCS}_{2}^{-}=\right.$Dithiocarboxylato, $\mathrm{R}=$ Methyl or Ethyl). J. Am. Chem. Soc. 2008, 130, $14102-14104$.

(10) Moriyama, H.; Otsubo, K.; Aoki, K.; Maesato, M.; Sugimoto, K.; Kitagawa, H. A Novel Platinum(III)-Platinum(III) Neutral Dimer Complex, $\quad \mathrm{Pt}_{2}$ (cdtb) $\mathrm{I}_{2} \quad$ (cdtb: 4-Cyanodithiobenzoate). Chem. Lett. 2019, 48, 1035-1037.

(11) Hübschle, C. B.; Sheldrick, G. M.; Dittrich, B. ShelXle: a Qt graphical user interface for SHELXL. J. Appl. Crystallogr. 2011, 44, 1281-1284.

(12) CrysAlis ${ }^{\text {Pro }}$ : Agilent Technologies Ltd, Yarnton, England (2014). 